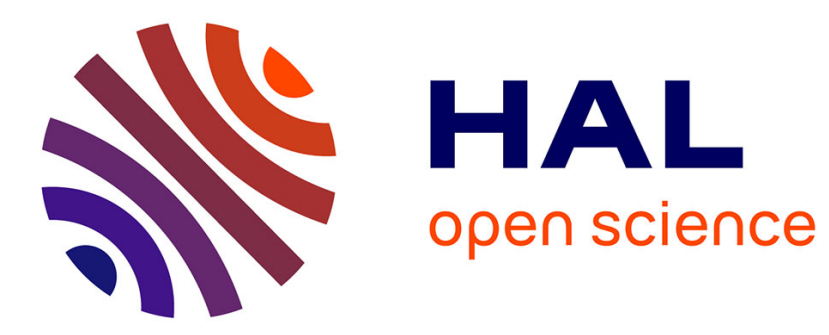

\title{
Targeting Infrequent Driver Alterations in Non-Small Cell Lung Cancer
}

Marie-Julie Nokin, Chiara Ambrogio, Ernest Nadal, David Santamaria

\section{To cite this version:}

Marie-Julie Nokin, Chiara Ambrogio, Ernest Nadal, David Santamaria. Targeting Infrequent Driver Alterations in Non-Small Cell Lung Cancer. Trends in Cancer, 2020, Online ahead of print. 10.1016/j.trecan.2020.11.005 . inserm-03082472

HAL Id: inserm-03082472 https://www.hal.inserm.fr/inserm-03082472

Submitted on 18 Dec 2020

HAL is a multi-disciplinary open access archive for the deposit and dissemination of scientific research documents, whether they are published or not. The documents may come from teaching and research institutions in France or abroad, or from public or private research centers.
L'archive ouverte pluridisciplinaire HAL, est destinée au dépôt et à la diffusion de documents scientifiques de niveau recherche, publiés ou non, émanant des établissements d'enseignement et de recherche français ou étrangers, des laboratoires publics ou privés. 
Marie-Julie NOKIN ${ }^{1}$, Chiara AMBROGIO ${ }^{2,3}$, Ernest NADAL ${ }^{4 *}$ and David SANTAMARIA ${ }^{1 *}$

$3{ }^{1}$ University of Bordeaux, INSERM U1218, ACTION Laboratory, IECB, 33600 Pessac, France

$4{ }^{2}$ Department of Molecular Biotechnology and Health Sciences, Molecular Biotechnology

5 Center, University of Torino, Torino, Italy

$6{ }^{3}$ Department of Medical Oncology, Dana-Farber Cancer Institute, Boston, MA 02215, USA

$7{ }^{4}$ Department of Medical Oncology, Catalan Institute of Oncology, Clinical Research in Solid

8 Tumors (CReST) Group, Oncobell Program, IDIBELL, L'Hospitalet, Barcelona, Spain

$9 \quad{ }^{*}$ Corresponding authors

\section{Address for correspondence}

Ernest Nadal: Department of Medical Oncology, Catalan Institute of Oncology, Clinical Research in Solid Tumors (CReST) Group, Oncobell Program, IDIBELL, Gran Via de I'Hospitalet 199, 08908 L'Hospitalet de Llobregat, Barcelona, Spain. E-mail: esnadal@iconcologia.net

David Santamaria: University of Bordeaux, INSERM U1218, ACTION Laboratory, IECB, 2 Rue 


\section{Abstract}

The discovery of oncogenic driver mutations led to the development of targeted therapies with non-small cell lung cancer (NSCLC) being a paradigm for precision medicine in this setting. Nowadays, the number of clinical trials focusing on targeted therapies for uncommon drivers is growing exponentially, emphasizing the medical need for these patients. Unfortunately, similar to what is observed with most targeted therapies directed against a driver oncogene, the clinical response is almost always temporary and acquired resistance to these drugs invariably emerges. Here, we review the biology of infrequent genomic actionable alterations in NSCLC as well as the current and emerging therapeutic options for these patients. Mechanisms leading to acquired drug resistance and future challenges in the field are also discussed.

\section{Glossary}

Epithelial to mesenchymal transition (EMT): process by which epithelial cells lose their epithelial phenotype and gain mesenchymal properties.

MAPKsignaling pathway: signaling cascade (RAS-RAF-MEK-ERK) that mediates signals from cell surface receptors regulating cell growth, differentiation and survival.

Median progression-free survival (mPFS): length of time during and after the treatment that a patient lives with the disease and does not get worse.

Non-small cell lung cancer (NSCLC): major subtype of lung cancer (accounts for $80-90 \%$ of all lung cancers) comprising both squamous neoplasms and adenocarcinoma (LUAD).

Objective/overall response rate (ORR): proportion of patients in a trial whose tumor is significantly reduced by a drug.

\section{The challenge of targeted therapy in NSCLC driven by uncommon genetic alterations}

The expanding spectrum of oncogenic driver mutations and clinically available signaling pathway inhibitors had a major impact on non-small cell lung cancer (NSCLC) (see Glossary) patients management in the last decade [1]. Cancer driver mutations not only initiate the disease but also sustain tumor progression and therefore their inhibition results in a therapeutic benefit. Driver oncogenes are often identified due to their recurrence in patients, a complicated feature when they appear with low prevalence as those covered in 
this review. Yet the oncogenic nature and the addiction of cancer cells to this set of infrequent drivers have been clearly established as well as their mutually exclusive pattern with other oncogenes. With the exception of BRAF, all belong to the receptor tyrosine kinase (RTK) family and when in the oncogenic form constantly activate essential downstream signaling pathways, including the MAPK (see Glossary), PI3K and JNK, resulting in sustained growth, increased survival and enhanced dissemination. Recently, Food and Drug Administration (FDA) has approved specific inhibitors targeting infrequent NSCLC oncogenic drivers (ROS1, MET, RET, BRAF, and NTRK). Beyond those, promising preliminary data with compounds targeting other emerging driver alterations (e.g. HER2) have been reported [2]. Used as first or latter lines of treatment (after standard chemotherapy and/or immunotherapy), these targeted therapies have greatly increased patients' outcome [3-9]. Unfortunately, as anticipated by the lessons learned from the clinical management of EGFRmutated and $A L K$-rearranged LUAD (Box 1), therapeutic resistance eventually appears in most patients and, therefore, advanced NSCLC remains largely incurable (for review see [10]). In the present review, we describe the biological relevance and the therapeutic options of a series of infrequent drivers for which clinical treatments have been approved or are under evaluation. Likewise, the clinical management of on-target resistance is discussed per driver while that due to bypass signaling is collectively addressed given its pan-driver conservation.

\section{ROS1}

\section{Biological and clinical features}

ROS1 is a conserved orphan RTK initially identified in glioblastoma and was the first chromosomal rearrangement described in NSCLC [11]. Since then, several ROS1 breakpoints have been described involving the entire ROS1 kinase domain and accounting for $1-2 \%$ of NSCLC. Twenty fusion partners (e.g. SLC34A2, EZR and SDC4) have been reported, among which CD74-ROS1 is the most common [12-14]. Whether distinct partners are functionally equivalent is unknown, although in vitro data indicates that they impose changes in subcellular localization affecting signaling and oncogenic properties [15]. Unlike $A L K$ rearrangements, most of the known ROS1 fusion partners lack constitutive dimerization domains and the mechanism of ROS1 oncogenic activation remains unknown. Along with RET and NTRK, ROS1 rearrangements are associated with younger age at diagnosis, none or 
low tobacco exposure and generally have adenocarcinoma histology [16, 17]. Diagnosis of ROS1 fusions by immunohistochemistry (IHC) is the most cost-effective method requiring confirmation by break-apart probe fluorescent in situ hybridization (FISH) or hybrid RNAbased next-generation sequencing (NGS) if the RNA quality is optimal $[18,19]$.

\section{Frontline targeted therapy}

ROS1-positive lung cancer seems particularly sensitive to pemetrexed-based chemotherapy [20]. The ALK inhibitor crizotinib was supposed to efficiently target ROS1-rearranged tumors given that ROS1 and ALK belong to the insulin receptor superfamily [21] sharing $>80 \%$ of amino acid sequence within their ATP-binding sites. Furthermore, crizotinib binds with high affinity to both kinases and inhibiting cell line proliferation. Indeed, this hypothesis was corroborated in the clinic with crizotinib showing marked therapeutic effect in patients with ROS1-rearranged NSCLC [22]. Accordingly, crizotinib, first approved for the treatment of $A L K$ rearranged NSCLC, received FDA and European Medicines Agency (EMA) expanded approval in 2016 for ROS1-rearranged NSCLC [22-26] (Figure 1 and Table 1). Similarly, in 2020, entrectinib has obtained FDA and EMA approval in this tumor type [8, 27]. In addition, other kinase inhibitors including ceritinib and lorlatinib have been evaluated in ROS1-positive crizotinib naïve NSCLC [28, 29] (Figure 1 and Table 1).

\section{Addressing on-target mechanisms of resistance}

The accumulated knowledge after a decade of using RTKi for the treatment of ALK- and EGFR-mutant LUAD (Box 1) anticipated that the selection of on-target mutations within the kinase domain would be the main mechanism of acquired resistance in ROS1 and the rest of infrequent drivers covered in this review. Indeed, several mutations have been reported affecting the solvent-front, the gatekeeper residue, the activation loop or the DFG motifs and all are predicted to prevent drug binding due to steric hindrance. Figure $2 \mathrm{~A}$ summarizes the different on-target mutations identified and their functional analogy among the different drivers together with ALK and EGFR for comparative purposes.

Fortunately, also guided by the successful clinical management of resistant disease in EGFRand ALK-mutant patients (Box 1), new generation inhibitors have been identified or purposely designed to combat drug resistance. Figure 2B summarizes pre-clinical and clinical data regarding the sensitivities of the most common secondary mutations to a panel of inhibitors for each driver. In the case of ROS1, resistance profiling studies using both in vitro 
and in vivo models demonstrated that cabozantinib (and its structural analog foretinib) as well as DS-6051b (a novel ATP-competitive ROS1/NTRK inhibitor) markedly inhibited the growth of ROS1 G2032R mutants [30-35]. Indeed, several case reports of ROS1-rearranged LUAD patients resistant to crizotinib and ceritinib reported responses to cabozantinib [36, 37]. With similar efficacy, DS-6051b had better toxicity profile [38] and two ongoing clinical trials are evaluating its efficacy in ROS1-rearranged NSCLC ${ }^{i, i i}$. In addition, repotrectinib (TPX0005), a selective and highly potent TKI against ROS1, NTRK, and ALK, demonstrated potent anti-proliferative activity against the G2032R and D2033N ROS1 mutations in cellular inhibitory assays and xenografts [39]. This has been tentatively confirmed in a clinical setting (TRIDENT-1, NCT03093116) reporting that repotrectinib achieved tumor regression in 45\% of patients with ROS1-positive NSCLC resistant to prior $\operatorname{TKI}(\mathrm{s})[40,41]$. Interestingly, not all ontarget mutations are equally sensitive to new generation inhibitors and patient stratification will be required. Indeed, each TKI is structurally distinct with varying degrees of activity against the different resistance mutations, giving them unique activity profiles. This is illustrated by lorlatinib that demonstrated promising activity in 40 patients with ROS1positive NSCLC who progressed to crizotinib with an overall response rate (ORR, see Glossary) of $35 \%$ and a median progression-free survival (mPFS, see Glossary) of 8.5 months. While patients harboring K1991Q and S1986F ROS1 mutations achieved durable responses to lorlatinib, none of the patients with the more frequent G2032R mutation did benefit [29].

\section{NTRK}

\section{Biological and clinical features}

The Neurotrophic Tropomyosin Receptor Kinase (NTRK) genes (NTRK1, 2 and 3) encode TRKA, TRKB and TRKC, respectively. They are activated by a family of four ligands (NGF, BDNF, NT-3 and NT-4) known as neurotrophins that display different affinities for each RTK and play essential roles in the development and function of the nervous system. Activating mutations in NTRK have been identified in NSCLC, yet their oncogenic role remains controversial [42]. Similarly, activating splice variants and overexpression have been reported in pan-cancer studies but, undoubtedly, the most frequent aberrations involve intra- and inter-chromosomal gene-fusions implicating NTRK that occur at a frequency below $0.4 \%$ in NSCLC. The biology of NTRK oncogenes has been comprehensively reviewed 
elsewhere $[43,44]$. Of note, a NTRK fusion was the first non-RAS oncogene identified almost 40 years ago (indicated as OncD in [45]; for review see [46]). Of the three NTRK, pan-cancerrelated fusions more commonly affect NTRK1 and NTRK3, and 48 different partners have been reported [47]. In lung, the fusions involve NTRK1 and NTRK3 with five and two distinct partners respectively, being ETV6-NTRK3 the most prevalent $[47,48]$. The NGS-based FoundationOneCDx test has just received FDA-approval for the identification of NTRK fusions.

\section{Frontline targeted therapy}

Early phase basket trials of solid tumors harboring NTRK gene rearrangements were performed with first-generation TKIs such as larotrectinib, which is selective for TRKA/B/C, and entrectinib, which targets TRKA/B/C as well as ALK and ROS1. Both compounds have demonstrated marked tumor-agnostic efficacy in pan cancer trials [6, 7] (Figure 1 and Table 1). Based on these results larotrectinib received accelerated FDA approval for the treatment of TRK fusion-positive cancers in 2018 followed by entrectinib one year later. Both drugs also obtained histology-independent approval in solid tumors harboring NTRK rearrangements by EMA. Ongoing trials may help to better estimate efficacy and duration of response in NSCLC.

\section{Addressing on-target mechanisms of resistance}

Next-generation TRK inhibitors, such as selitrectinib (LOXO-195) and repotrectinib (TPX0005), have been designed to combat on-target acquired resistance mutations and their activity is being evaluated in phase I/II trials or compassionate use protocols for NTRKaltered cancers. Indeed, selitrectinib was developed as a second-generation TRK inhibitor using modeling studies even before acquired resistance appeared in the clinic. An initial evaluation performed on a first-in-human basis proved its activity against solvent-front and xDFG mutants inducing rapid tumor responses [49]. This has been extended in an ongoing phase I/II trial upon enrolling patients with prior treatment with NTRK inhibitors $\mathrm{sii}^{\mathrm{ii}}$. Preliminary results indicate an ORR of $45 \%$ in patients with mutations affecting the kinase domain [50]. Similarly, repotrectinib evaluation in a phase I/II first-in-human dose-escalation study (NCT03093116) demonstrated efficacy in patients harboring NTRK3 solvent front resistant mutations [39]. Whether these next-generation TRK inhibitors will exert a similar benefit in resistant LUAD patients with kinase-domain acquired mutations is still unknown. 


\section{Biological and clinical features}

Unlike other RTKs, RET (트arranged during Iransfection) does not directly bind to its ligands but requires an additional co-receptor. Indeed, ligands of the glial cell line-derived neurotrophic factor (GDNF) family bind to one of the four receptors of the GDNF family receptor- $\alpha$ (GFR $\alpha$ ), which subsequently allow RET dimerization, autophosphorylation and activation [51]. Despite a few studies reporting concomitant genomic alterations (for review see [52]), RET rearrangements are considered mutually exclusive with other alterations in NSCLC indicating an independent carcinogenic role and have been identified in $1-2 \%$ of cases. Chromosomal inversions or translocations involving RET results in a juxtaposition of its kinase domain and the coiled coil domain of the partner. Similar to the oncogenic activation of ALK fusions, this coiled coil domain is responsible of the ligand-independent homodimerization and constitutive RET activation [53]. In NSCLC, up to 12 fusion partners (e.g. CCDC6, NCOA4, TRIM33) have been described with the most frequent being KIF5B [54]. Unlike $A L K$ and ROS1 rearrangements, RET fusion genes cannot be adequately detected by IHC due to low sensitivity and highly variable specificity [52]. Therefore, NGS is the most accurate option as FISH and RT-PCR may lead to false negatives due to technical limitations.

\section{Frontline targeted therapy}

Similar to $A L K$ and ROS1-positive tumors, durable benefits have been obtained with pemetrexed-based chemotherapy in RET-rearranged NSCLC [55]. Considering the structural similarities of both the kinase domain and the ATP-binding site with other RTKs [56], several multi-kinase inhibitors (MKIs; e.g. vandetanib, cabozantinib, lenvatinib as well as alectinib, a VEGFR-sparing MKI) were initially used for the treatment of patients bearing RET fusions (for review see $[52,57,58]$ ) (Figure 1 and Table 1). Recently, more specific and potent RET inhibitors are under investigation. These include pralsetinib (BLU-667) and selpercatinib (LOXO-292), which have received FDA approval for RET-altered NSCLC [4, 5, 59-61] (Figure 1 and Table 1).

Treatment evolution of RET-driven disease is an illustrative example of the continuous need to design specific and potent inhibitors. New putative oncogenic fusions are being discovered $[62,63]$ that could also require initial treatment with less-efficient MKIs in parallel to the development of specific compounds.

\section{Addressing on-target mechanisms of resistance}


The differential response of various on target mutants has also been reported in $R E T$-altered tumors. Whereas most MKIs are ineffective against resistant mutations, both ponatinib [64] and AD80 [65] showed pre-clinical efficacy against specific mutations (V804 and G810).

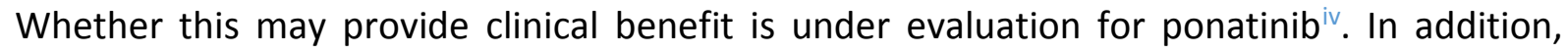
while pralsetinib displayed inhibitor activity against V804M/L and S904F mutations but failed to inhibit G810 alterations [60], TPX-0046, a structurally different RET/SRC inhibitor, showed potent in vitro and in vivo activity against the RET solvent-front mutation G810R and is currently tested in a phase $\mathrm{I} / \mathrm{II}$ trial $^{v}$.

\section{MET}

\section{Biological and clinical features}

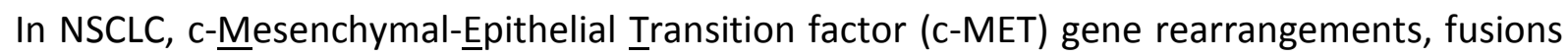
and somatic mutations have been identified but are rare [66]. MET overexpression, however, is frequent in unselected NSCLC patients although its clinical value is unclear as this criterion is largely dependent on the antibody assay and the determination of a positive threshold. MET amplification is also a common mechanism of resistance to EGFR-TKIs in NSCLC. Anyhow, increased expression is considered a causative driver only if co-occurring with clinically relevant $M E T$ genomic alterations like $M E T$ gene amplification or mutations resulting in exon 14 skipping (META14). This alteration results in a MET protein lacking the juxtamembrane domain with extended half-life after ligand stimulation and is considered an oncogenic driver. META14 is predominantly associated to sarcomatoid carcinoma histology $[67,68]$ and detected in $2-4 \%$ of NSCLC patients while MET amplification affects approximately $2 \%$ of LUAD.

Several MET inhibitors, including TKIs and monoclonal antibodies against MET or its ligand HGF have been assessed in NSCLC (for review see $[69,70]$ ). Various agents have reached phase III trials and failed in patients with MET alterations, illustrating the need for better stratification upfront. Indeed, a significant fraction of patients display co-existing oncogenes and only a small fraction of highly amplified tumors may actually be bona-fide MET-addicted cases, which are associated to more effective responses to targeted therapies [71]. 
Crizotinib received FDA approval for $A L K$ and ROS1 NSCLC patients but was initially developed as a MET inhibitor [72]. Significant clinical activity was reported in patients harboring METS14 alterations including complete responses. Yet, the ORR of crizotinib in this cohort was lower compared to those achieved with targeted therapies for other NSCLC drivers [73] (Figure 1 and Table 1). Neither variations in the mutation type or splice-site region nor the MET copy number appear to be major differentiating response factors, so the underlying causes of the heterogeneous clinical outcome are unknown. Novel and highly selective type Ib MET inhibitors such as tepotinib and capmatinib have been evaluated in phase II trials $[9,74]$ (Figure 1 and Table 1). In general, META14 tumors display lower initial response rates to TKIs compared to other RTK drivers in NSCLC. This could be due to high rate of co-existing genomic alterations inducing both MAPK and PI3K pathway activation resulting in innate/primary resistance $[75,76]$.

\section{Addressing on-target mechanisms of resistance}

In the case of MET-resistant disease, mutations like those affecting the Y1230 and D1228 residues may predict response to type II MET inhibitors such as cabozantinib and glesatinib [77]. Others, including substitutions implicating L1195 or F1200, may not be sensitive to treatment with these compounds as they preclude binding to the DFG-out pocket [75]. In a similar study, 7 out of 20 (35\%) META14 patients who progressed to MET TKI had on-target kinase domain mutations (H1094, G1163, L1195, D1228, Y1230) or elevated MET amplification. Cabozantinib has also been shown to be active against the D1228V mutation with concomitant MET amplification [78].

\section{HER2/ERBB2}

\section{Biological and clinical features}

Human epidermal growth factor receptor 2 (HER2), also called ERBB2, is one of the four members of the EGFR family. It remains an orphan receptor activated by heterodimerization with other ERBB family members (for review see[79]). In NSCLC, HER2 dysregulations can be caused by gene amplification, protein overexpression and mutations. Despite the efficacy of anti-HER2 agents in breast and gastric cancer, clinical interest on HER2-positive NSCLC was dampened when the first clinical trials evaluating trastuzumab, an anti-HER2 humanized antibody reported negative results $[80,81]$. In parallel, HER2 kinase domain mutations were 
identified in NSCLC patients not associated with HER2 amplification/overexpression [82, 83]. These results were further confirmed [84] indicating that HER2 amplification and mutations represent two distinct oncogenic drivers and potential therapeutic targets. These findings, coupled with the encouraging results of TKIs in EGFR mutants, launched the clinical evaluation of anti-HER2 agents specifically in NSCLC patients bearing HER2 mutations (90\% of them are located in exon 20). HER2 exon 20 alterations comprise point mutations (e.g. L755S, V777L and G776C) or, more frequently, insertions [85]. The most prevalent (over $80 \%$ ) is a 12 base pair in-frame insertion causing duplication of amino acids YVMA at codon 775 (A775_G776insYVMA) [86]. Mutations in exon 20 are analogous to EGFR exon 20 mutations and lead to HER2 constitutive activation [87-89]. Overall, HER2 mutations account for $2-4 \%$ of the NSCLC cases and tend to be women and light/never smokers with LUAD histology [85].

\section{Frontline targeted therapy}

HER2 targeted therapy is not yet standard of care in NSCLC and, currently, chemotherapies remain the main strategy. Patients with HER2-mutant LUAD, especially YVMA insertion, demonstrated a markedly inferior response to first line pemetrexed-based chemotherapy compared to those harboring ALK/ROS1 rearrangements, which strengthen the need for effective anti-HER2 agents [90]. Retrospectives studies displayed encouraging disease control rates in NSCLC patients bearing HER2 exon 20 insertions treated with HER2-targeted drugs [91, 92]. Several clinical studies have been carried out or are ongoing using both antiHER2 antibodies and small molecules (for review see [2]) (Figure 1 and Table 1). Among these compounds, poziotinib, a pan-HER TKI, has structural features that can circumvent the steric changes induced by exon 20 insertions and increase its affinity compared to larger TKIs [93]. Next-generation TKIs with increased selectivity towards the EGFR and HER2 mutants (such as TAK-788) are being developed to limit the toxicity associated to wild-type EGFR inhibition [94, 95]. In addition, trastuzumab and its antibody-drug conjugate, trastuzumabemtansine (T-DM1), showed mixed results in the clinic due in part to the molecular heterogeneity of HER2-altered NSCLC (for review see [2]). Trastuzumab-deruxtecan (DS8201a) showed promising efficacy among NSCLC patients with HER2 exon 20 mutations [96] (Figure 1 and Table 1). In this context, patients with HER2-mutated NSCLC often develop brain metastases with disease progression and trastuzumab would be inefficient due to its 
inability to cross the blood-brain barrier. Therefore, monitoring and treatment of CNS metastases may require specific approaches.

\section{BRAF}

\section{Biological and clinical features}

BRAF, together with ARAF and CRAF, constitute the RAF family of serine/threonine kinases, a core component of the MAPK cascade. Since the first evidence in 2002 [97], almost 200 distinct BRAF mutations have been reported in around $8 \%$ of cancers. In NSCLC, they represent $1.5-3.5 \%$ of the cases and affect the kinase domain, either in the glycine-rich loop in exon 11 or in the activation segment in exon 15, resulting in increased ERK signaling (for review see [98]). Clinical characteristics associated with BRAF mutations in lung cancer vary without obvious segregation in specific parameters, except the significant association with LUAD histology. Most patients with BRAF mutations are smokers, although patients with V600 mutations are more likely to be light/never-smokers compared with patients with nonV600 mutations [99-102]. BRAF mutations as well as HER2 and MET alterations are generally well covered by NGS gene panels. BRAF mutants are classified in three categories [103]. Class 1 (V600) and class 2 (G464, G469, L597 and K601) mutants are mutually exclusive, RASindependent and signal constitutively as active monomers or active dimers, respectively. Class 3 (e.g. G466 and D594) have impaired/null kinase activity and activation of downstream signaling is RAS- and CRAF-dependent and sensitive to ERK-mediated feedback. In this case, RAS is generally activated by RTK signaling [103]. Notably, expression of an endogenous class 3 BRAF mutant triggers LUAD in mice, indicating that kinase-inactive BRAF isoforms are oncogenic drivers [104].

\section{Frontline targeted therapy}

Experience with BRAF-mutant melanoma has heavily influenced the management of NSCLC. Targeted therapy has evolved from BRAF monotherapy to combined BRAF/MEK inhibition showing superior efficacy and favorable safety profile in BRAF V600E-mutant NSCLC [3, 105109] (Figure 1 and Table 1). The combination of dabrafenib plus trametinib has received both FDA and EMA approval for the treatment of metastatic NSCLC harboring the BRAF V600E mutation regardless of previous therapies. Another pair of BRAF and MEK inhibitors, 
encorafenib and binimetinib, is under investigation and has shown encouraging CNS activity in a patient with BRAF V600E-mutated LUAD [110].

Next-generation RAF inhibitors have been reported to be active in BRAF-mutant NSCLC in the clinic (for review see [111]). Notably, the pan-RAF inhibitor PLX8394 selectively disrupts both BRAF homo- and BRAF-CRAF heterodimers [112, 113]. Furthermore, a phase I study evaluating ulixertinib, a first-in-class ERK inhibitor, reported partial responses in NSCLC patients bearing both V600 and non-V600 mutations as well as CNS activity [114]. In addition, BRAF-mutant NSCLC is likely to have high level of PD-L1 expression [115]. When treated with immune checkpoint inhibitors, no significant differences in ORR and MPFS were reported among V600E and non-V600E mutants. The optimal therapeutic sequence has yet to be established in both V600 and non-V600 (Box 2) BRAF-mutated LUAD patients.

\section{Signaling bypass activation and other resistance mechanisms}

In accordance with EGFR- and ALK-driven NSCLC (Box 1), the development of resistance to targeted therapies in lung cancer bearing infrequent alterations also implicates signaling bypass tracks, although the underlying molecular mechanisms are less understood. The activation of bypass pathways described so far in both preclinical and clinical studies are depicted for each uncommon driver in Figure 3.

Alterations affecting the RAS-MAPK pathway or upstream receptors are the most frequent. Notably, EGFR [116-119] and HER2 [120,121] activating mutations or amplification have been reported in ROS1- and MET-altered patients after progressing to crizotinib. Interestingly, EGFR activation may not only contribute to the resistant phenotype by supporting bypass signaling but also by protein-protein interactions that reactivate druginhibited ROS1 [118]. EGFR signaling has also been identified as a critical adaptive survival mechanism to RET $[118,122,123]$ and NTRK [118] blockade in NSCLC preclinical models. Beside EGFR and HER2, other RTKs have been associated to drug resistance in lung cancer. Particularly, MET amplification has been identified in afatinib-resistance cell lines harboring HER2 alterations [124], in pralsetinib resistant RET-rearranged tumors [125] and in entrectinib resistant NTRK-rearranged biopsies [126]. Furthermore, FGFR autocrine pathway activation through FGF1 secretion was shown to be associated with increased sensitivity to FGFR inhibitor in resistant BRAF V600E LUAD [127]. 
In addition, KRAS and NRAS mutations on codons 12 and 61 have been identified both in preclinical models of resistance to MKIs in RET-altered cells [123] and in MET, NTRK and $B R A F$-altered patients after progressing to frontline targeted therapies [126, 128-132]. Similarly, MEK1 activating mutations were described in case reports of BRAF V600E NSCLC after progression to dabrafenib and trametinib [133] as well as in NTRK-rearranged patients after TKIs treatment [126]. Furthermore, case-reports highlighted BRAF V600E mutation or amplification in post-treatment biopsies of ROS1, NTRK and META14-altered NSCLC patients $[126,129,134,135]$. Intriguingly, RTK-RAS-MAPK activating mutations tend to be mutually exclusive in primary tumors, a finding justified due to functional redundancy and lack of selective advantage. However, several studies have demonstrated that synthetic toxicity due to excessive signaling could equally underlie oncogene incompatibility [136-138]. In this context, intermittent therapy resulting in excessive signaling proves to be advantageous in drug resistant melanoma harboring co-existing oncogenes [139]. Yet, in NSCLC, this approach could only be applied to certain oncogenic combinations [140]. Additional clinical support from both prospective and retrospective studies is required to validate this therapeutic strategy.

Another frequently altered pathway upon TKI treatment is PI3K-AKT-mTOR. Indeed, activating mutations of PIK3CA have been reported in both ROS1-altered [135, 141] and HER2 exon 20-mutated patients [142] after progression to targeted therapies. Finally, other alterations potentially contributing to drug resistance have been reported such as KIT [143] and c-myc [144] in preclinical models of ROS1 and MET-altered NSCLC, respectively. Additionally, acquired amplification of $M D M 2$, which encodes the E3 ubiquitinprotein ligase MDM2, has been identified in RET-rearranged cabozantinib-resistant patients [145]. Likewise, the Hippo pathway with its effector YAP has been recognized as a mechanism of resistance to BRAF and MEK targeted therapy in both preclinical and clinical samples bearing BRAF V600 mutations [146]. Yet, given their low prevalence, their clinical significance requires further confirmation. Importantly, the activation of bypass signaling pathways often results in the acquisition of vulnerabilities that could be therapeutically exploited. In a recent study, novel activating MAPK alterations (deletions of several nucleotides in MAP3K1 and MAP2K1 as well as NF1 loss-of-function mutations) were acquired in patients harboring ROS1-rearranged tumors being treated with ROS1 inhibitors. Cells bearing these alterations are resistant to ROS1-TKIs 
but sensitive to a combination of ROS1 and MEK inhibitors in vitro and in vivo [147]. Importantly, a METS14-altered patient who acquired a KRAS gain after crizotinib treatment achieved clinical response upon addition of trametinib [75]. The identification of PIK3CA or PTEN mutations suggests that activation of the PI3K-AKTmTOR pathway could represent an acquired vulnerability and supports the potential use of mTOR inhibitors for the treatment of resistant NSCLC. In a phase I clinical trial, a BRAF V600E-mutated NSCLC patient who progressed to single-agent dabrafenib and multiple lines of chemotherapy achieved a partial response with the combination vemurafenib plus everolimus, a mTOR inhibitor [148]. Preliminary results from a clinical trial (NCT01582191) combining vandetanib and the mTOR inhibitor everolimus showed significant activity in RETpositive NSCLC [149] as well as CNS responses [150]. Overall, combined inhibition of uncommon drivers and bypass signaling pathway (either with mTOR inhibitors or MEK inhibitors) could be a promising therapeutic strategy that should be assessed in resistant patients lacking on-target resistance mutations.

Finally, phenotypic changes such as epithelial to mesenchymal transition (EMT) (see Glossary) has been reported in one ROS1 crizotinib-resistant patient lacking resistant ROS1 mutations or alternative pathway mutations [117]. EMT along with acquisition of cancer stem cell-like properties have been identified in both TKI resistant MET- and HER2alteredcell lines $[124,151]$. No cases of histological transformation to a small-cell lung cancer (SCLC), a phenomenon observed in EGFR and ALK TKI-resistant tumors, has been reported so far in the context of uncommon drivers.

\section{Concluding remarks and future perspectives}

Alongside EGFR- and ALK-driven NSCLC, patients bearing infrequent drivers display limited benefit from targeted therapies due to the onset of resistance. Despite the growing body of evidence about their clinical management many key knowledge gaps remain (see Outstanding Questions). First, lung cancers genomes display substantial heterogeneity and complex branching evolution that can be influenced by treatment-imposed selective pressure [152-154]. The understanding of the subclonal origin of resistance in the context of rare drivers will require deep sequencing studies of either multiregional biopsies or single tumor cells that are currently missing. This information could help develop tailored treatments to tackle resistance by anticipating the emergence of on-target or bypass 
mechanisms. Interestingly, recent preclinical evidence has demonstrated that enhanced therapeutic benefit and delayed onset of resistance upon multiple low dosing of different nodes within the same pathway [155]. Beside targeted therapies, these patients may benefit from combining chemotherapy and immunotherapy, but further information is needed. Recent retrospective studies highlighted that immune checkpoint inhibitors may provide an effective option for NSCLC patients with certain infrequent alterations, especially in those associated with smoking such as BRAF mutations $[115,156,157]$. Future clinical trials should determine the ideal regimen of combination therapies including dosing and nature of targeted agents, anti-angiogenic drugs and/or chemo plus immunotherapy. When defining the ideal clinical regimen caution should be applied if transposing information from other cancer types harboring the same infrequent driver. For example, the extended survival upon combinatorial treatments in BRAF V600E mutant melanoma has also been achieved in LUAD patients. However, the therapeutic response of colorectal carcinoma patients bearing the same alteration was disappointing due to EGFR-mediated intrinsic resistance [158]. In any case, an ideal clinical regimen would require radiological and molecular monitoring of disease progression. Resistance mechanisms could be captured by non-invasive methods like liquid biopsy [119, 125, 159] (see Outstanding Questions). A recurrent and important problem is the occurrence of brain metastases, thereby requiring the use of compounds with good intracranial activity. In conclusion, a better understanding of the alterations underlying the development of resistance and the design of tailored treatments will allow delaying tumor progression and achieving improved clinical outcomes in NSCLC patients bearing infrequent alterations.

\section{Box 1. Targeting EGFR and ALK alterations in NSCLC}

EGFR mutations occur in 15\% of NSCLC, being in-frame deletion in exon 19 (19Del) or L858R mutation the most frequent. Both first-generation (erlotinib and gefitinib) and secondgeneration (afatinib) inhibitors demonstrated more durable responses than chemotherapy [160-164], receiving FDA-approval as first-line treatments in 2013 and 2014. In almost half of patients treated with these compounds, resistance is mediated by the T790M gatekeeper mutation (equivalent to those described in ROS1, RET and NTRK, Figure 2A). Thirdgeneration EGFR inhibitors such as osimertinib demonstrated impressive response in 
patients with EGFR T790M-positive NSCLC after progression on early-generation TKIs, receiving FDA-approval in 2017 [165]. Due to its ability to spare wild-type EGFR, inhibit EGFR 19Del/L858R/T790M and CNS penetration, osimertinib is approved as first-line treatment since 2018 [166]. Unfortunately, new resistance mechanisms have emerged like the tertiary C797S mutation affecting the covalent binding of the drug $[167,168]$ or the development of T790 wild-type clones [169].

$A L K$ rearrangements are observed in $5 \%$ of NSCLC, being EML4-ALK the most prevalent. At least 15 EML4-ALK variants have been identified so far, with some expressed as multiple isoforms [170]. All contain the ALK entire intracellular kinase domain (exons 20-29) but differ in the breakpoint with the EML4 gene. First-generation crizotinib received FDA approval in 2011, becoming the first approved ALK inhibitor for NSCLC [171]. Almost one third of crizotinib-treated patients acquire resistance by kinase domain mutations, being L1196M gatekeeper and G1269A mutations the most frequent. In 2014, second-generation ALK inhibitor ceritinib was approved after confirmation of its efficacy in both crizotinib-naïve and crizotinib-resistant patients with L1196M and G1269A/S mutations [172, 173]. In approximately half of cases, resistance is caused by emergence of additional ALK mutations, the most common being the solvent-front substitution G1202R. Therefore, two other second-generation ALK inhibitors - alectinib and brigatinib - were granted accelerated FDA approval for $A L K$-positive patients who had failed on crizotinib treatment, demonstrating superior inhibitory profile against all known 17 secondary $A L K$ mutations $[174,175]$. Both alectinib and brigatinib were later approved also as first line therapy in treatment-naïve patients, although alectinib has become the preferred agent. Recently, the third-generation ALK/ROS1 inhibitor lorlatinib, specifically designed to target resistance mutations and to penetrate the blood-brain barrier, received accelerated FDA approval for the treatment of patients with $A L K$-rearranged advanced NSCLC after progression on crizotinib and at least one other ALK inhibitor [176]. The phase III trial CROWN comparing lorlatinib with crizotinib as first-line therapy is currently ongoing ${ }^{\mathrm{vi}}$.

\section{Box 2. BRAF non-V600 mutations in NSCLC}

While more than $90 \%$ of BRAF-altered melanoma bear a V600 mutation, BRAF-positive NSCLC are equally divided in V600 and non-V600 mutations and, therefore, represent one of 
potential of many of the rare BRAF mutations has yet to be demonstrated in vivo. In addition, data demonstrating clinical activity of MAPK-directed therapies in non-V600 BRAFmutant lung cancers are lacking. Therefore, there is currently no consensus on how to optimally manage patients with class 2 and $3 B R A F$ mutations. In the EURAF retrospective series that included 6 NSCLC patients with BRAF mutations other than V600E, only one patient (G596V) achieved a partial response to Vemurafenib [105]. These findings are consistent with the statement that class 2 and 3 mutants signal as RAF dimers rather than monomers [103], making them resistant to the BRAF monomer inhibitors. However, in vitro, both class 2 and 3 mutated cell lines are sensitive to MEK inhibition [177]. Additionally, the combination of BRAF and MEK inhibitors enhanced MAPK inhibition and cell proliferation reduction in both class 2 and 3 BRAF-mutant NSCLC preclinical models compared to MEK inhibitor alone [178-181]. Interestingly, oncogenic signaling triggered by class 3 BRAF mutants depends on a variety of RTKs that should be identified per patient [103]. Alternatively, the inhibition of SHP2, a scaffold protein downstream of RTKs promoting RAS activation, or the use of pan-RTK inhibitors (such as afatinib) could be considered [182]. Incidentally, concomitant SHP2 and BRAF/MEK inhibition showed synergistic effects in a class 3 BRAF-mutant cell line [183]. Additionally, allosteric inhibitors targeting the heterodimer interface between BRAF class 3 mutants with CRAF may represent an alternative approach [184]. Further studies are required to (1) precise the molecular mechanisms of each BRAF mutants (i.e. homo versus heterodimer), (2) define the importance of the additional molecular determinants that may play a role in modulating therapeutic response (i.e. expression level of CRAF and concomitant genetic alterations) and (3) identify the most promising strategies with potential drug combination to achieve successful clinical response in patients with non-V600 BRAF mutations. 
512 E. N. participated in advisory boards from Bristol Myers Squibb, Merck Sharpe \& Dohme, 513 Lilly, Roche, Pfizer, Takeda, Boehringer Ingelheim, Amgen and AstraZeneca. E. N. has 514 received research funding from Roche and Pfizer. All other authors have nothing to disclose.

\section{Acknowledgements}

516 This work was supported by grants from INCA (PIbio19-190), Siric-BRIO and a Senior Chair 517 Idex-Université de Bordeaux (2016-0396) to D.S.E.N. received support from the Department 518 of Health of the Government of Catalonia and from the Spanish Society of Medical Oncology 519 (SEOM) Foundation. We thank CERCA Program / Generalitat de Catalunya for their 520 institutional support and grant 2017SGR448.M-J.N. was supported by a bourse d'excellence 521 de la Fédération Wallonie-Bruxelles (WBI) and a postdoctoral fellowship from Fondation ARC 522 pour la recherché contre le cancer. C.A. laboratory is supported by the Giovanni Armenise523 Harvard Foundation and the Lung Cancer Research Foundation (LCRF).

$\underline{\text { Resources }}$

' https://clinicaltrials.gov/ct2/show/NCT02279433

527

ii https://clinicaltrials.gov/ct2/show/NCT02675491

528 iii https://clinicaltrials.gov/ct2/show/NCT03215511

529

iv https://clinicaltrials.gov/ct2/show/NCT01813734

530

${ }^{\vee}$ https://clinicaltrials.gov/ct2/show/NCT04161391

531

vi https://clinicaltrials.gov/ct2/show/NCT03052608

532 


\section{References}

1 Rosell, R. and Karachaliou, N. (2016) Large-scale screening for somatic mutations in lung cancer. Lancet 387, 1354-1356

2 Baraibar, l., et al. (2020) Novel drugs targeting EGFR and HER2 exon 20 mutations in metastatic NSCLC. Critical reviews in oncology/hematology 148, 102906 3 Planchard, D., et al. (2016) Dabrafenib plus trametinib in patients with previously treated BRAF(V600E)-mutant metastatic non-small cell lung cancer: an open-label, multicentre phase 2 trial. The Lancet. Oncology 17, 984-993 4 Drilon, A., et al. (2020) Efficacy of Selpercatinib in RET Fusion-Positive Non-Small-Cell Lung Cancer. The New England journal of medicine 383, 813-824

5 Gainor, J.F., et al. (2020) Registrational dataset from the phase I/II ARROW trial of pralsetinib (BLU667 ) in patients (pts) with advanced RET fusion+ non-small cell lung cancer (NSCLC). Journal of Clinical Oncology 38, 9515-9515

6 Hong, D.S., et al. (2020) Larotrectinib in patients with TRK fusion-positive solid tumours: a pooled analysis of three phase $1 / 2$ clinical trials. The Lancet. Oncology 21, 531-540

7 Doebele, R.C., et al. (2020) Entrectinib in patients with advanced or metastatic NTRK fusion-positive solid tumours: integrated analysis of three phase 1-2 trials. The Lancet. Oncology 21, 271-282 8 Drilon, A., et al. (2020) Entrectinib in ROS1 fusion-positive non-small-cell lung cancer: integrated analysis of three phase 1-2 trials. The Lancet. Oncology 21, 261-270

9 Wolf, J., et al. (2020) Capmatinib in MET Exon 14-Mutated or MET-Amplified Non-Small-Cell Lung Cancer. The New England journal of medicine 383, 944-957

10 Rotow, J. and Bivona, T.G. (2017) Understanding and targeting resistance mechanisms in NSCLC. Nature reviews. Cancer 17, 637-658

11 Rikova, K., et al. (2007) Global survey of phosphotyrosine signaling identifies oncogenic kinases in lung cancer. Cell 131, 1190-1203

12 Liu, Y., et al. (2019) Identification of a novel WNK1-ROS1 fusion in a lung adenocarcinoma sensitive to crizotinib. Lung cancer 129, 92-94

$13 \mathrm{Xu}, \mathrm{S} .$, et al. (2019) ROS1-ADGRG6: a case report of a novel ROS1 oncogenic fusion variant in lung adenocarcinoma and the response to crizotinib. BMC cancer 19, 769

14 Lin, J.J. and Shaw, A.T. (2017) Recent Advances in Targeting ROS1 in Lung Cancer. Journal of thoracic oncology : official publication of the International Association for the Study of Lung Cancer $12,1611-1625$

15 Neel, D.S., et al. (2019) Differential Subcellular Localization Regulates Oncogenic Signaling by ROS1 Kinase Fusion Proteins. Cancer research 79, 546-556

16 Lin, J.J., et al. (2017) ROS1 Fusions Rarely Overlap with Other Oncogenic Drivers in Non-Small Cell Lung Cancer. Journal of thoracic oncology : official publication of the International Association for the Study of Lung Cancer 12, 872-877

17 Wang, R., et al. (2012) RET fusions define a unique molecular and clinicopathologic subtype of non-small-cell lung cancer. Journal of clinical oncology : official journal of the American Society of Clinical Oncology 30, 4352-4359

18 Lindeman, N.I., et al. (2018) Updated Molecular Testing Guideline for the Selection of Lung Cancer Patients for Treatment With Targeted Tyrosine Kinase Inhibitors: Guideline From the College of American Pathologists, International Association for the Study of Lung Cancer, and Association for Molecular Pathology. Journal of Thoracic Oncology 13, 323-358

19 Davies, K.D., et al. (2018) Comparison of Molecular Testing Modalities for Detection of ROS1 Rearrangements in a Cohort of Positive Patient Samples. Journal of thoracic oncology : official publication of the International Association for the Study of Lung Cancer 13, 1474-1482 20 Chen, Y.F., et al. (2016) Efficacy of Pemetrexed-Based Chemotherapy in Patients with ROS1 Fusion-Positive Lung Adenocarcinoma Compared with in Patients Harboring Other Driver Mutations in East Asian Populations. Journal of thoracic oncology : official publication of the International Association for the Study of Lung Cancer 11, 1140-1152 
21 Robinson, D.R., et al. (2000) The protein tyrosine kinase family of the human genome. Oncogene $19,5548-5557$

22 Shaw, A.T., et al. (2014) Crizotinib in ROS1-rearranged non-small-cell lung cancer. The New England journal of medicine 371, 1963-1971

23 Moro-Sibilot, D., et al. (2019) Crizotinib in c-MET- or ROS1-positive NSCLC: results of the AcSe phase II trial. Annals of oncology : official journal of the European Society for Medical Oncology 30, 1985-1991

24 Mazieres, J., et al. (2015) Crizotinib therapy for advanced lung adenocarcinoma and a ROS1 rearrangement: results from the EUROS1 cohort. Journal of clinical oncology : official journal of the American Society of Clinical Oncology 33, 992-999

25 Wu, Y.L., et al. (2018) Phase II Study of Crizotinib in East Asian Patients With ROS1-Positive Advanced Non-Small-Cell Lung Cancer. Journal of clinical oncology : official journal of the American Society of Clinical Oncology 36, 1405-1411

26 Michels, S., et al. (2019) Safety and Efficacy of Crizotinib in Patients With Advanced or Metastatic ROS1-Rearranged Lung Cancer (EUCROSS): A European Phase II Clinical Trial. Journal of thoracic oncology : official publication of the International Association for the Study of Lung Cancer 14, 12661276

27 Drilon, A., et al. (2017) Safety and Antitumor Activity of the Multitargeted Pan-TRK, ROS1, and ALK Inhibitor Entrectinib: Combined Results from Two Phase I Trials (ALKA-372-001 and STARTRK-1). Cancer discovery 7, 400-409

28 Lim, S.M., et al. (2017) Open-Label, Multicenter, Phase II Study of Ceritinib in Patients With NonSmall-Cell Lung Cancer Harboring ROS1 Rearrangement. Journal of clinical oncology : official journal of the American Society of Clinical Oncology 35, 2613-2618

29 Shaw, A.T., et al. (2019) Lorlatinib in advanced ROS1-positive non-small-cell lung cancer: a multicentre, open-label, single-arm, phase 1-2 trial. The Lancet. Oncology 20, 1691-1701 30 Davare, M.A., et al. (2015) Structural insight into selectivity and resistance profiles of ROS1 tyrosine kinase inhibitors. Proceedings of the National Academy of Sciences of the United States of America 112, E5381-5390 31 Davare, M.A., et al. (2013) Foretinib is a potent inhibitor of oncogenic ROS1 fusion proteins. Proceedings of the National Academy of Sciences of the United States of America 110, 19519-19524 32 Zou, H.Y., et al. (2015) PF-06463922 is a potent and selective next-generation ROS1/ALK inhibitor capable of blocking crizotinib-resistant ROS1 mutations. Proceedings of the National Academy of Sciences of the United States of America 112, 3493-3498 33 Chong, C.R., et al. (2017) Identification of Existing Drugs That Effectively Target NTRK1 and ROS1 Rearrangements in Lung Cancer. Clinical cancer research : an official journal of the American Association for Cancer Research 23, 204-213 34 Katayama, R., et al. (2015) Cabozantinib overcomes crizotinib resistance in ROS1 fusion-positive cancer. Clinical cancer research : an official journal of the American Association for Cancer Research 21, 166-174

35 Katayama, R., et al. (2019) The new-generation selective ROS1/NTRK inhibitor DS-6051b overcomes crizotinib resistant ROS1-G2032R mutation in preclinical models. Nature communications 10,3604

36 Drilon, A., et al. (2016) A Novel Crizotinib-Resistant Solvent-Front Mutation Responsive to Cabozantinib Therapy in a Patient with ROS1-Rearranged Lung Cancer. Clinical cancer research : an official journal of the American Association for Cancer Research 22, 2351-2358 37 Sun, T.Y., et al. (2019) Lengthy Progression-Free Survival and Intracranial Activity of Cabozantinib in Patients with Crizotinib and Ceritinib-Resistant ROS1-Positive Non-Small Cell Lung Cancer. Journal of thoracic oncology : official publication of the International Association for the Study of Lung Cancer 14, e21-e24

38 Fujiwara, Y., et al. (2018) Safety and pharmacokinetics of DS-6051b in Japanese patients with nonsmall cell lung cancer harboring ROS1 fusions: a phase I study. Oncotarget 9, 23729-23737 
39 Drilon, A., et al. (2018) Repotrectinib (TPX-0005) Is a Next-Generation ROS1/TRK/ALK Inhibitor That Potently Inhibits ROS1/TRK/ALK Solvent- Front Mutations. Cancer discovery 8, 1227-1236 40 Ou, S., et al. (2018) OA09 Preliminary Clinical Activity of Repotrectinib (TPX-0005) in Advanced ROS1 Fusion-Positive Non-Small Cell Lung Cancer. Journal of Thoracic Oncology 13, S1047 41 Cho, B.C., et al. (2019) Safety and preliminary clinical activity of repotrectinib in patients with advanced ROS1 fusion-positive non-small cell lung cancer (TRIDENT-1 study). Journal of Clinical Oncology 37, 9011-9011

42 Harada, T., et al. (2011) Role and relevance of TrkB mutations and expression in non-small cell lung cancer. Clinical cancer research : an official journal of the American Association for Cancer Research 17, 2638-2645

43 Vaishnavi, A., et al. (2015) TRKing down an old oncogene in a new era of targeted therapy. Cancer discovery $5,25-34$

44 Cocco, E., et al. (2018) NTRK fusion-positive cancers and TRK inhibitor therapy. Nature reviews. Clinical oncology 15, 731-747

45 Pulciani, S., et al. (1982) Oncogenes in solid human tumours. Nature 300, 539-542 46 Barbacid, M. (2019) On the right TRK: from oncogene discovery to cancer therapeutics. Annals of oncology : official journal of the European Society for Medical Oncology 30 Suppl 8, viii3-viii4

47 Rosen, E.Y., et al. (2020) TRK Fusions Are Enriched in Cancers with Uncommon Histologies and the Absence of Canonical Driver Mutations. Clinical cancer research : an official journal of the American Association for Cancer Research 26, 1624-1632

48 Farago, A.F., et al. (2018) Clinicopathologic Features of Non-Small-Cell Lung Cancer Harboring an NTRK Gene Fusion. JCO precision oncology 2018 49 Drilon, A., et al. (2017) A Next-Generation TRK Kinase Inhibitor Overcomes Acquired Resistance to Prior TRK Kinase Inhibition in Patients with TRK Fusion-Positive Solid Tumors. Cancer discovery 7 , 963-972

50 Hyman, D., et al. (2019) Abstract CT127: Phase I and expanded access experience of LOXO-195 (BAY 2731954), a selective next-generation TRK inhibitor (TRKi). Cancer research 79, CT127-CT127 51 Mulligan, L.M. (2014) RET revisited: expanding the oncogenic portfolio. Nature reviews. Cancer 14, 173-186

52 Ferrara, R., et al. (2018) Clinical and Translational Implications of RET Rearrangements in NonSmall Cell Lung Cancer. Journal of thoracic oncology : official publication of the International Association for the Study of Lung Cancer 13, 27-45

$53 \mathrm{Ju}$, Y.S., et al. (2012) A transforming KIF5B and RET gene fusion in lung adenocarcinoma revealed from whole-genome and transcriptome sequencing. Genome research 22, 436-445

54 Gautschi, O., et al. (2017) Targeting RET in Patients With RET-Rearranged Lung Cancers: Results From the Global, Multicenter RET Registry. Journal of clinical oncology : official journal of the American Society of Clinical Oncology 35, 1403-1410 55 Drilon, A., et al. (2016) Clinical outcomes with pemetrexed-based systemic therapies in RETrearranged lung cancers. Annals of oncology : official journal of the European Society for Medical Oncology 27, 1286-1291

56 Knowles, P.P., et al. (2006) Structure and chemical inhibition of the RET tyrosine kinase domain. The Journal of biological chemistry 281, 33577-33587

57 Drilon, A., et al. (2018) Targeting RET-driven cancers: lessons from evolving preclinical and clinical landscapes. Nature reviews. Clinical oncology 15, 150

58 Bronte, G., et al. (2019) Targeting RET-rearranged non-small-cell lung cancer: future prospects. Lung Cancer (Auckl) 10, 27-36

59 Subbiah, V., et al. (2018) Precision Targeted Therapy with BLU-667 for RET-Driven Cancers. Cancer discovery 8, 836-849

60 Solomon, B.J., et al. (2020) RET Solvent Front Mutations Mediate Acquired Resistance to Selective RET Inhibition in RET-Driven Malignancies. Journal of thoracic oncology : official publication of the International Association for the Study of Lung Cancer 15, 541-549 
61 Evans, E., et al. (2019) P2.03-44 BLU-667 Demonstrates Robust Activity in RET Fusion-Driven Intracranial Tumor Models. Journal of Thoracic Oncology 14, S701

62 Zhuo, M., et al. (2020) Analysis of MET kinase domain rearrangement in NSCLC. Lung cancer 145, 140-143

63 Reddy, V.P., et al. (2017) BRAF fusions in clinically advanced non-small cell lung cancer: An emerging target for anti-BRAF therapies. Journal of Clinical Oncology 35, 9072-9072

64 Huang, Q., et al. (2016) Preclinical Modeling of KIF5B-RET Fusion Lung Adenocarcinoma. Molecular cancer therapeutics 15, 2521-2529

65 Plenker, D., et al. (2017) Drugging the catalytically inactive state of RET kinase in RET-rearranged tumors. Science translational medicine 9

66 Campbell, J.D., et al. (2016) Distinct patterns of somatic genome alterations in lung adenocarcinomas and squamous cell carcinomas. Nature genetics 48, 607-616 67 Cancer Genome Atlas Research, N. (2014) Comprehensive molecular profiling of lung adenocarcinoma. Nature 511, 543-550

68 Tong, J.H., et al. (2016) MET Amplification and Exon 14 Splice Site Mutation Define Unique Molecular Subgroups of Non-Small Cell Lung Carcinoma with Poor Prognosis. Clinical cancer research : an official journal of the American Association for Cancer Research 22, 3048-3056

69 Pasquini, G. and Giaccone, G. (2018) C-MET inhibitors for advanced non-small cell lung cancer. Expert opinion on investigational drugs 27, 363-375

70 Liang, H. and Wang, M. (2020) MET Oncogene in Non-Small Cell Lung Cancer: Mechanism of MET Dysregulation and Agents Targeting the HGF/c-Met Axis. OncoTargets and therapy 13, 2491-2510 71 Noonan, S.A., et al. (2016) Identifying the Appropriate FISH Criteria for Defining MET Copy Number-Driven Lung Adenocarcinoma through Oncogene Overlap Analysis. Journal of thoracic oncology : official publication of the International Association for the Study of Lung Cancer 11, 12931304

72 Cui, J.J., et al. (2011) Structure based drug design of crizotinib (PF-02341066), a potent and selective dual inhibitor of mesenchymal-epithelial transition factor (c-MET) kinase and anaplastic lymphoma kinase (ALK). Journal of medicinal chemistry 54, 6342-6363

73 Drilon, A., et al. (2020) Antitumor activity of crizotinib in lung cancers harboring a MET exon 14 alteration. Nature medicine 26, 47-51

74 Paik, P.K., et al. (2020) Tepotinib in Non-Small-Cell Lung Cancer with MET Exon 14 Skipping Mutations. The New England journal of medicine

75 Rotow, J.K., et al. (2020) Co-occurring Alterations in the RAS-MAPK Pathway Limit Response to MET Inhibitor Treatment in MET Exon 14 Skipping Mutation-Positive Lung Cancer. Clinical cancer research : an official journal of the American Association for Cancer Research 26, 439-449

76 Jamme, P., et al. (2020) Alterations in the PI3K Pathway Drive Resistance to MET Inhibitors in NSCLC Harboring MET Exon 14 Skipping Mutations. Journal of thoracic oncology : official publication of the International Association for the Study of Lung Cancer 15, 741-751

77 Engstrom, L.D., et al. (2017) Glesatinib Exhibits Antitumor Activity in Lung Cancer Models and Patients Harboring MET Exon 14 Mutations and Overcomes Mutation-mediated Resistance to Type I MET Inhibitors in Nonclinical Models. Clinical cancer research : an official journal of the American Association for Cancer Research 23, 6661-6672

78 Bahcall, M., et al. (2016) Acquired METD1228V Mutation and Resistance to MET Inhibition in Lung Cancer. Cancer discovery 6, 1334-1341

79 Yarden, Y. and Sliwkowski, M.X. (2001) Untangling the ErbB signalling network. Nature reviews. Molecular cell biology 2, 127-137

80 Gatzemeier, U., et al. (2004) Randomized phase II trial of gemcitabine-cisplatin with or without trastuzumab in HER2-positive non-small-cell lung cancer. Annals of oncology : official journal of the European Society for Medical Oncology 15, 19-27

81 Clamon, G., et al. (2005) Lack of trastuzumab activity in nonsmall cell lung carcinoma with overexpression of erb-B2: 39810: a phase II trial of Cancer and Leukemia Group B. Cancer 103, 16701675 
82 Shigematsu, H., et al. (2005) Somatic mutations of the HER2 kinase domain in lung adenocarcinomas. Cancer research 65, 1642-1646 83 Stephens, P., et al. (2004) Lung cancer: intragenic ERBB2 kinase mutations in tumours. Nature 431, 525-526

84 Li, B.T., et al. (2016) HER2 Amplification and HER2 Mutation Are Distinct Molecular Targets in Lung Cancers. Journal of thoracic oncology : official publication of the International Association for the Study of Lung Cancer 11, 414-419

85 Pillai, R.N., et al. (2017) HER2 mutations in lung adenocarcinomas: A report from the Lung Cancer Mutation Consortium. Cancer 123, 4099-4105 86 Arcila, M.E., et al. (2012) Prevalence, clinicopathologic associations, and molecular spectrum of ERBB2 (HER2) tyrosine kinase mutations in lung adenocarcinomas. Clinical cancer research : an official journal of the American Association for Cancer Research 18, 4910-4918 87 Perera, S.A., et al. (2009) HER2YVMA drives rapid development of adenosquamous lung tumors in mice that are sensitive to BIBW2992 and rapamycin combination therapy. Proceedings of the National Academy of Sciences of the United States of America 106, 474-479 88 Shimamura, T., et al. (2006) Non-small-cell lung cancer and Ba/F3 transformed cells harboring the ERBB2 G776insV_G/C mutation are sensitive to the dual-specific epidermal growth factor receptor and ERBB2 inhibitor HKI-272. Cancer research 66, 6487-6491

89 Wang, S.E., et al. (2006) HER2 kinase domain mutation results in constitutive phosphorylation and activation of HER2 and EGFR and resistance to EGFR tyrosine kinase inhibitors. Cancer cell 10, 25-38 90 Wang, Y., et al. (2018) Outcomes of Pemetrexed-based chemotherapies in HER2-mutant lung cancers. BMC cancer 18,326

91 Mazieres, J., et al. (2016) Lung cancer patients with HER2 mutations treated with chemotherapy and HER2-targeted drugs: results from the European EUHER2 cohort. Annals of oncology : official journal of the European Society for Medical Oncology 27, 281-286 92 Mazieres, J., et al. (2013) Lung cancer that harbors an HER2 mutation: epidemiologic characteristics and therapeutic perspectives. Journal of clinical oncology : official journal of the American Society of Clinical Oncology 31, 1997-2003 93 Robichaux, J.P., et al. (2018) Mechanisms and clinical activity of an EGFR and HER2 exon 20selective kinase inhibitor in non-small cell lung cancer. Nature medicine 24, 638-646 94 Chouitar, J., et al. (2018) P2.13-32 TAK-788 is a Novel and Potent Tyrosine Kinase Inhibitor with Selective Activity Against EGFR/HER2. Journal of Thoracic Oncology 13, S811 95 Neal, J., et al. (2018) P1.13-44 Safety, PK, and Preliminary Antitumor Activity of the Oral EGFR/HER2 Exon 20 Inhibitor TAK-788 in NSCLC. Journal of Thoracic Oncology 13, S599 96 Smit, E.F., et al. (2020) Trastuzumab deruxtecan (T-DXd; DS-8201) in patients with HER2-mutated metastatic non-small cell lung cancer (NSCLC): Interim results of DESTINY-Lung01. Journal of Clinical Oncology 38, 9504-9504

97 Davies, H., et al. (2002) Mutations of the BRAF gene in human cancer. Nature 417, 949-954 98 Holderfield, M., et al. (2014) Targeting RAF kinases for cancer therapy: BRAF-mutated melanoma and beyond. Nature reviews. Cancer 14, 455-467

99 Leonetti, A., et al. (2018) BRAF in non-small cell lung cancer (NSCLC): Pickaxing another brick in the wall. Cancer treatment reviews 66, 82-94 100 Auliac, J.B., et al. (2018) Patients with non-small-cell lung cancer harbouring a BRAF mutation: a multicentre study exploring clinical characteristics, management, and outcomes in a real-life setting: EXPLORE GFPC 02-14. Current oncology 25, e398-e402

101 Litvak, A.M., et al. (2014) Clinical characteristics and course of 63 patients with BRAF mutant lung cancers. Journal of thoracic oncology : official publication of the International Association for the Study of Lung Cancer 9, 1669-1674

102 Tissot, C., et al. (2016) Clinical characteristics and outcome of patients with lung cancer harboring BRAF mutations. Lung cancer 91, 23-28

103 Yao, Z., et al. (2017) Tumours with class 3 BRAF mutants are sensitive to the inhibition of activated RAS. Nature 548, 234-238 
104 Nieto, P., et al. (2017) A Braf kinase-inactive mutant induces lung adenocarcinoma. Nature 548, 239-243

105 Gautschi, O., et al. (2015) Targeted Therapy for Patients with BRAF-Mutant Lung Cancer: Results from the European EURAF Cohort. Journal of thoracic oncology : official publication of the International Association for the Study of Lung Cancer 10, 1451-1457

106 Mazieres, J., et al. (2020) Vemurafenib in non-small-cell lung cancer patients with BRAF(V600) and BRAF(nonV600) mutations. Annals of oncology : official journal of the European Society for Medical Oncology 31, 289-294

107 Subbiah, V., et al. (2019) Efficacy of Vemurafenib in Patients With Non-Small-Cell Lung Cancer With BRAF V600 Mutation: An Open-Label, Single-Arm Cohort of the Histology-Independent VEBASKET Study. JCO precision oncology, 1-9

108 Planchard, D., et al. (2016) Dabrafenib in patients with BRAF(V600E)-positive advanced nonsmall-cell lung cancer: a single-arm, multicentre, open-label, phase 2 trial. The Lancet. Oncology 17, 642-650 109 Planchard, D., et al. (2017) Dabrafenib plus trametinib in patients with previously untreated BRAF(V600E)-mutant metastatic non-small-cell lung cancer: an open-label, phase 2 trial. The Lancet. Oncology 18, 1307-1316

110 McLoughlin, E.M., et al. (2019) Clinical and Radiographic Response of Leptomeningeal and Brain Metastases to Encorafenib and Binimetinib in a Patient With BRAF V600E-Mutated Lung Adenocarcinoma. Journal of thoracic oncology : official publication of the International Association for the Study of Lung Cancer 14, e269-e271

111 Karoulia, Z., et al. (2017) New perspectives for targeting RAF kinase in human cancer. Nature reviews. Cancer $17,676-691$

112 Okimoto, R.A., et al. (2016) Preclinical efficacy of a RAF inhibitor that evades paradoxical MAPK pathway activation in protein kinase BRAF-mutant lung cancer. Proceedings of the National Academy of Sciences of the United States of America 113, 13456-13461

113 Yao, Z., et al. (2019) RAF inhibitor PLX8394 selectively disrupts BRAF dimers and RASindependent BRAF-mutant-driven signaling. Nature medicine 25, 284-291 114 Sullivan, R.J., et al. (2018) First-in-Class ERK1/2 Inhibitor Ulixertinib (BVD-523) in Patients with MAPK Mutant Advanced Solid Tumors: Results of a Phase I Dose-Escalation and Expansion Study. Cancer discovery 8, 184-195

115 Dudnik, E., et al. (2018) BRAF Mutant Lung Cancer: Programmed Death Ligand 1 Expression, Tumor Mutational Burden, Microsatellite Instability Status, and Response to Immune Check-Point Inhibitors. Journal of thoracic oncology : official publication of the International Association for the Study of Lung Cancer 13, 1128-1137

116 Davies, K.D., et al. (2013) Resistance to ROS1 inhibition mediated by EGFR pathway activation in non-small cell lung cancer. PloS one 8, e82236 117 Song, A., et al. (2015) Molecular Changes Associated with Acquired Resistance to Crizotinib in ROS1-Rearranged Non-Small Cell Lung Cancer. Clinical cancer research : an official journal of the American Association for Cancer Research 21, 2379-2387 118 Vaishnavi, A., et al. (2017) EGFR Mediates Responses to Small-Molecule Drugs Targeting Oncogenic Fusion Kinases. Cancer research 77, 3551-3563

119 Dagogo-Jack, I., et al. (2017) Circulating Tumor DNA Identifies EGFR Coamplification as a Mechanism of Resistance to Crizotinib in a Patient with Advanced MET-Amplified Lung Adenocarcinoma. Journal of thoracic oncology : official publication of the International Association for the Study of Lung Cancer 12, e155-e157 120 McCoach, C.E., et al. (2018) Resistance Mechanisms to Targeted Therapies in ROS1(+) and ALK(+) Non-small Cell Lung Cancer. Clinical cancer research : an official journal of the American Association for Cancer Research 24, 3334-3347 121 Ding, G., et al. (2019) Case report: HER2 amplification as a resistance mechanism to crizotinib in NSCLC with MET exon 14 skipping. Cancer biology \& therapy 20, 837-842 
122 Chang, H., et al. (2017) EGF Induced RET Inhibitor Resistance in CCDC6-RET Lung Cancer Cells.

842 Yonsei medical journal 58, 9-18

843123 Nelson-Taylor, S.K., et al. (2017) Resistance to RET-Inhibition in RET-Rearranged NSCLC Is

844 Mediated By Reactivation of RAS/MAPK Signaling. Molecular cancer therapeutics 16, 1623-1633

845124 Torigoe, H., et al. (2018) Therapeutic strategies for afatinib-resistant lung cancer harboring HER2

846 alterations. Cancer science 109, 1493-1502

847125 Lin, J.J., et al. (2020) Mechanisms of Resistance to Selective RET Tyrosine Kinase Inhibitors in RET

848 Fusion-Positive Non-Small Cell Lung Cancer. Annals of oncology : official journal of the European

849 Society for Medical Oncology

850126 Cocco, E., et al. (2019) Resistance to TRK inhibition mediated by convergent MAPK pathway

851 activation. Nature medicine 25, 1422-1427

852

853

854

855

856

857

858

859

860

861

862

863

864

865

866

867

868

869

870

871

872

873

874

875

876

877

878

879

880

881

882

883

884

885

886

887

888

889

890 127 Wang, V.E., et al. (2019) Adaptive Resistance to Dual BRAF/MEK Inhibition in BRAF-Driven Tumors through Autocrine FGFR Pathway Activation. Clinical cancer research : an official journal of the American Association for Cancer Research 25, 7202-7217

128 Riedel, R., et al. (2019) Acquired KRAS mutation and loss of low-level MET amplification after durable response to crizotinib in a patient with lung adenocarcinoma. Lung cancer 133, 20-22 129 Recondo, G., et al. (2020) Molecular Mechanisms of Acquired Resistance to MET Tyrosine Kinase Inhibitors in Patients with MET Exon 14-Mutant NSCLC. Clinical cancer research : an official journal of the American Association for Cancer Research 26, 2615-2625

130 Rudin, C.M., et al. (2013) Molecular characterization of acquired resistance to the BRAF inhibitor dabrafenib in a patient with BRAF-mutant non-small-cell lung cancer. Journal of thoracic oncology: official publication of the International Association for the Study of Lung Cancer 8, e41-42 131 Abravanel, D.L., et al. (2018) An Acquired NRAS Q61K Mutation in BRAF V600E-Mutant Lung Adenocarcinoma Resistant to Dabrafenib Plus Trametinib. Journal of thoracic oncology : official publication of the International Association for the Study of Lung Cancer 13, e131-e133 132 Niemantsverdriet, M., et al. (2018) KRAS Mutation as a Resistance Mechanism to BRAF/MEK Inhibition in NSCLC. Journal of thoracic oncology : official publication of the International Association for the Study of Lung Cancer 13, e249-e251

133 Facchinetti, F., et al. (2020) Molecular mechanisms of resistance to BRAF and MEK inhibitors in BRAF(V600E) non-small cell lung cancer. European journal of cancer 132, 211-223

134 Watanabe, J., et al. (2018) Appearance of a BRAF Mutation Conferring Resistance to Crizotinib in Non-Small Cell Lung Cancer Harboring Oncogenic ROS1 Fusion. Journal of thoracic oncology : official publication of the International Association for the Study of Lung Cancer 13, e66-e69

135 Dagogo-Jack, I., et al. (2019) Molecular Analysis of Plasma From Patients With ROS1-Positive NSCLC. Journal of thoracic oncology : official publication of the International Association for the Study of Lung Cancer 14, 816-824

136 Ambrogio, C., et al. (2017) In vivo oncogenic conflict triggered by co-existing KRAS and EGFR activating mutations in lung adenocarcinoma. Oncogene 36, 2309-2318

137 Unni, A.M., et al. (2015) Evidence that synthetic lethality underlies the mutual exclusivity of oncogenic KRAS and EGFR mutations in lung adenocarcinoma. eLife 4, e06907

138 Cisowski, J., et al. (2016) Oncogene-induced senescence underlies the mutual exclusive nature of oncogenic KRAS and BRAF. Oncogene 35, 1328-1333

139 Hong, A., et al. (2018) Exploiting Drug Addiction Mechanisms to Select against MAPKi-Resistant Melanoma. Cancer discovery 8, 74-93

140 Sale, M.J., et al. (2019) MEK1/2 inhibitor withdrawal reverses acquired resistance driven by BRAF(V600E) amplification whereas KRAS(G13D) amplification promotes EMT-chemoresistance. Nature communications 10, 2030

$141 \mathrm{Xu}$, C.W., et al. (2017) Patient harboring a novel PIK3CA point mutation after acquired resistance to crizotinib in an adenocarcinoma with ROS1 rearrangement: A case report and literature review. Thoracic cancer 8, 714-719 
142 Chuang, J.C., et al. (2017) ERBB2-Mutated Metastatic Non-Small Cell Lung Cancer: Response and Resistance to Targeted Therapies. Journal of thoracic oncology : official publication of the International Association for the Study of Lung Cancer 12, 833-842 143 Dziadziuszko, R., et al. (2016) An Activating KIT Mutation Induces Crizotinib Resistance in ROS1Positive Lung Cancer. Journal of thoracic oncology : official publication of the International Association for the Study of Lung Cancer 11, 1273-1281

144 Shen, A., et al. (2015) c-Myc alterations confer therapeutic response and acquired resistance to c-Met inhibitors in MET-addicted cancers. Cancer research 75, 4548-4559

145 Somwar, R., et al. (2016) MDM2 amplification (Amp) to mediate cabozantinib resistance in patients (Pts) with advanced RET-rearranged lung cancers. Journal of Clinical Oncology 34, 9068-9068 146 Lin, L., et al. (2015) The Hippo effector YAP promotes resistance to RAF- and MEK-targeted cancer therapies. Nature genetics $47,250-256$

147 Sato, H., et al. (2020) MAPK pathway alterations correlate with poor survival and drive resistance to therapy in patients with lung cancers driven by ROS1 fusions. Clinical cancer research : an official journal of the American Association for Cancer Research 148 Subbiah, V., et al. (2018) Phase I Study of the BRAF Inhibitor Vemurafenib in Combination With the Mammalian Target of Rapamycin Inhibitor Everolimus in Patients With BRAF-Mutated Malignancies. JCO precision oncology, 1-12

149 Subbiah, V., et al. (2018) Multi-kinase RET inhibitor vandetanib combined with mTOR inhibitor everolimus in patients with RET rearranged non-small cell lung cancer. Journal of Clinical Oncology 36, 9035-9035 150 Subbiah, V., et al. (2015) Systemic and CNS activity of the RET inhibitor vandetanib combined with the mTOR inhibitor everolimus in KIF5B-RET re-arranged non-small cell lung cancer with brain metastases. Lung cancer 89, 76-79

151 Sugano, T., et al. (2015) Inhibition of ABCB1 Overcomes Cancer Stem Cell-like Properties and Acquired Resistance to MET Inhibitors in Non-Small Cell Lung Cancer. Molecular cancer therapeutics $14,2433-2440$

152 Nahar, R., et al. (2018) Elucidating the genomic architecture of Asian EGFR-mutant lung adenocarcinoma through multi-region exome sequencing. Nature communications 9, 216 153 Maynard, A., et al. (2020) Therapy-Induced Evolution of Human Lung Cancer Revealed by SingleCell RNA Sequencing. Cell 182, 1232-1251 e1222

154 Negrao, M.V., et al. (2020) Molecular Landscape of BRAF-Mutant NSCLC Reveals an Association Between Clonality and Driver Mutations and Identifies Targetable Non-V600 Driver Mutations. Journal of thoracic oncology : official publication of the International Association for the Study of Lung Cancer 15, 1611-1623

155 Fernandes Neto, J.M., et al. (2020) Multiple low dose therapy as an effective strategy to treat EGFR inhibitor-resistant NSCLC tumours. Nature communications 11, 3157 156 Mazieres, J., et al. (2019) Immune checkpoint inhibitors for patients with advanced lung cancer and oncogenic driver alterations: results from the IMMUNOTARGET registry. Annals of oncology: official journal of the European Society for Medical Oncology 30, 1321-1328 157 Guisier, F., et al. (2020) Efficacy and Safety of Anti-PD-1 Immunotherapy in Patients With Advanced NSCLC With BRAF, HER2, or MET Mutations or RET Translocation: GFPC 01-2018. Journal of thoracic oncology : official publication of the International Association for the Study of Lung Cancer $15,628-636$ 158 Corcoran, R.B., et al. (2018) Combined BRAF, EGFR, and MEK Inhibition in Patients with BRAF(V600E)-Mutant Colorectal Cancer. Cancer discovery 8, 428-443 159 Ortiz-Cuaran, S., et al. (2020) Circulating Tumor DNA Genomics Reveal Potential Mechanisms of Resistance to BRAF-Targeted Therapies in Patients with BRAF-Mutant Metastatic Non-Small Cell Lung Cancer. Clinical cancer research : an official journal of the American Association for Cancer Research 160 Maemondo, M., et al. (2010) Gefitinib or chemotherapy for non-small-cell lung cancer with mutated EGFR. The New England journal of medicine 362, 2380-2388 
161 Mitsudomi, T., et al. (2010) Gefitinib versus cisplatin plus docetaxel in patients with non-smallcell lung cancer harbouring mutations of the epidermal growth factor receptor (WJTOG3405): an open label, randomised phase 3 trial. The Lancet. Oncology 11, 121-128

162 Rosell, R., et al. (2012) Erlotinib versus standard chemotherapy as first-line treatment for European patients with advanced EGFR mutation-positive non-small-cell lung cancer (EURTAC): a multicentre, open-label, randomised phase 3 trial. The Lancet. Oncology 13, 239-246

163 Sequist, L.V., et al. (2013) Phase III study of afatinib or cisplatin plus pemetrexed in patients with metastatic lung adenocarcinoma with EGFR mutations. Journal of clinical oncology : official journal of the American Society of Clinical Oncology 31, 3327-3334

164 Zhou, C., et al. (2011) Erlotinib versus chemotherapy as first-line treatment for patients with advanced EGFR mutation-positive non-small-cell lung cancer (OPTIMAL, CTONG-0802): a multicentre, open-label, randomised, phase 3 study. The Lancet. Oncology 12, 735-742

165 Mok, T.S., et al. (2017) Osimertinib or Platinum-Pemetrexed in EGFR T790M-Positive Lung Cancer. The New England journal of medicine 376, 629-640

166 Soria, J.C., et al. (2018) Osimertinib in Untreated EGFR-Mutated Advanced Non-Small-Cell Lung Cancer. The New England journal of medicine 378, 113-125

167 Niederst, M.J., et al. (2015) The Allelic Context of the C797S Mutation Acquired upon Treatment with Third-Generation EGFR Inhibitors Impacts Sensitivity to Subsequent Treatment Strategies.

Clinical cancer research : an official journal of the American Association for Cancer Research 21, 39243933

168 Thress, K.S., et al. (2015) Acquired EGFR C797S mutation mediates resistance to AZD9291 in nonsmall cell lung cancer harboring EGFR T790M. Nature medicine 21, 560-562

169 Piotrowska, Z., et al. (2015) Heterogeneity Underlies the Emergence of EGFRT790 Wild-Type Clones Following Treatment of T790M-Positive Cancers with a Third-Generation EGFR Inhibitor. Cancer discovery 5, 713-722

170 Choi, Y.L., et al. (2008) Identification of novel isoforms of the EML4-ALK transforming gene in non-small cell lung cancer. Cancer research 68, 4971-4976

171 Kwak, E.L., et al. (2010) Anaplastic lymphoma kinase inhibition in non-small-cell lung cancer. The New England journal of medicine 363, 1693-1703

172 Shaw, A.T., et al. (2014) Ceritinib in ALK-rearranged non-small-cell lung cancer. The New England journal of medicine $370,1189-1197$

173 Soria, J.C., et al. (2017) First-line ceritinib versus platinum-based chemotherapy in advanced ALKrearranged non-small-cell lung cancer (ASCEND-4): a randomised, open-label, phase 3 study. Lancet 389, 917-929

174 Shaw, A.T., et al. (2016) Alectinib in ALK-positive, crizotinib-resistant, non-small-cell lung cancer: a single-group, multicentre, phase 2 trial. The Lancet. Oncology 17, 234-242

175 Camidge, D.R., et al. (2018) Brigatinib versus Crizotinib in ALK-Positive Non-Small-Cell Lung Cancer. The New England journal of medicine 379, 2027-2039

176 Solomon, B.J., et al. (2018) Lorlatinib in patients with ALK-positive non-small-cell lung cancer: results from a global phase 2 study. The Lancet. Oncology 19, 1654-1667

177 Pratilas, C.A., et al. (2008) Genetic predictors of MEK dependence in non-small cell lung cancer. Cancer research 68, 9375-9383

178 Noeparast, A., et al. (2017) Non-V600 BRAF mutations recurrently found in lung cancer predict sensitivity to the combination of Trametinib and Dabrafenib. Oncotarget 8, 60094-60108 179 Kim, S.Y., et al. (2019) Patient-Derived Cells to Guide Targeted Therapy for Advanced Lung Adenocarcinoma. Scientific reports 9, 19909 180 Joshi, M., et al. (2015) Trametinib with or without vemurafenib in BRAF mutated non-small cell lung cancer. PloS one 10, e0118210

181 Noeparast, A., et al. (2018) Type II RAF inhibitor causes superior ERK pathway suppression compared to type I RAF inhibitor in cells expressing different BRAF mutant types recurrently found in lung cancer. Oncotarget 9, 16110-16123 
182 Nichols, R.J., et al. (2018) RAS nucleotide cycling underlies the SHP2 phosphatase dependence of mutant BRAF-, NF1- and RAS-driven cancers. Nature cell biology 20, 1064-1073

183 Bracht, J.W.P., et al. (2019) BRAF Mutations Classes I, II, and III in NSCLC Patients Included in the SLLIP Trial: The Need for a New Pre-Clinical Treatment Rationale. Cancers 11

184 Cope, N.J., et al. (2020) Analyses of the oncogenic BRAF(D594G) variant reveal a kinaseindependent function of BRAF in activating MAPK signaling. The Journal of biological chemistry 295, 2407-2420

185 Yoh, K., et al. (2017) Vandetanib in patients with previously treated RET-rearranged advanced non-small-cell lung cancer (LURET): an open-label, multicentre phase 2 trial. The Lancet. Respiratory medicine 5, 42-50

186 Lee, S.H., et al. (2017) Vandetanib in pretreated patients with advanced non-small cell lung cancer-harboring RET rearrangement: a phase II clinical trial. Annals of oncology : official journal of the European Society for Medical Oncology 28, 292-297

187 Drilon, A., et al. (2016) Cabozantinib in patients with advanced RET-rearranged non-small-cell lung cancer: an open-label, single-centre, phase 2, single-arm trial. The Lancet. Oncology 17, 16531660

$188 \mathrm{Hida}, \mathrm{T}$., et al. (2019) A phase 2 study of lenvatinib in patients with RET fusion-positive lung adenocarcinoma. Lung cancer 138, 124-130

189 Drilon, A., et al. (2019) A Phase I/Ib Trial of the VEGFR-Sparing Multikinase RET Inhibitor RXDX105. Cancer discovery 9, 384-395

190 Peters, S., et al. (2018) Activity of Afatinib in Heavily Pretreated Patients With ERBB2 MutationPositive Advanced NSCLC: Findings From a Global Named Patient Use Program. Journal of thoracic oncology : official publication of the International Association for the Study of Lung Cancer 13, 18971905

191 Lai, W.V., et al. (2019) Afatinib in patients with metastatic or recurrent HER2-mutant lung cancers: a retrospective international multicentre study. European journal of cancer 109, 28-35 192 Dziadziuszko, R., et al. (2019) Afatinib in NSCLC With HER2 Mutations: Results of the Prospective, Open-Label Phase II NICHE Trial of European Thoracic Oncology Platform (ETOP). Journal of thoracic oncology : official publication of the International Association for the Study of Lung Cancer 14, 10861094

193 Kris, M.G., et al. (2015) Targeting HER2 aberrations as actionable drivers in lung cancers: phase II trial of the pan-HER tyrosine kinase inhibitor dacomitinib in patients with HER2-mutant or amplified tumors. Annals of oncology : official journal of the European Society for Medical Oncology 26, 14211427

194 Hyman, D.M., et al. (2018) HER kinase inhibition in patients with HER2- and HER3-mutant cancers. Nature 554, 189-194

195 Wang, Y., et al. (2019) HER2 exon 20 insertions in non-small-cell lung cancer are sensitive to the irreversible pan-HER receptor tyrosine kinase inhibitor pyrotinib. Annals of oncology : official journal of the European Society for Medical Oncology 30, 447-455

196 Robichaux, J.P., et al. (2019) Pan-Cancer Landscape and Analysis of ERBB2 Mutations Identifies Poziotinib as a Clinically Active Inhibitor and Enhancer of T-DM1 Activity. Cancer cell 36, 444-457 e447

197 Awad, M.M., et al. (2013) Acquired resistance to crizotinib from a mutation in CD74-ROS1. The New England journal of medicine 368, 2395-2401

198 Gainor, J.F., et al. (2017) Patterns of Metastatic Spread and Mechanisms of Resistance to Crizotinib in ROS1-Positive Non-Small-Cell Lung Cancer. JCO precision oncology 2017 199 Facchinetti, F., et al. (2016) Crizotinib-Resistant ROS1 Mutations Reveal a Predictive Kinase Inhibitor Sensitivity Model for ROS1- and ALK-Rearranged Lung Cancers. Clinical cancer research : an official journal of the American Association for Cancer Research 22, 5983-5991 200 Dagogo-Jack, I., et al. (2018) Emergence of a RET V804M Gatekeeper Mutation During Treatment With Vandetanib in RET-Rearranged NSCLC. Journal of thoracic oncology : official publication of the International Association for the Study of Lung Cancer 13, e226-e227 
201 Nakaoku, T., et al. (2018) A secondary RET mutation in the activation loop conferring resistance 1046 to vandetanib. Nature communications 9,625

1047202 Drilon, A., et al. (2018) Efficacy of Larotrectinib in TRK Fusion-Positive Cancers in Adults and 1048 Children. The New England journal of medicine 378, 731-739

$1049203 \mathrm{Koga}, \mathrm{T}$. , et al. (2018) Activity of a novel HER2 inhibitor, poziotinib, for HER2 exon 20 mutations 1050 in lung cancer and mechanism of acquired resistance: An in vitro study. Lung cancer 126, 72-79 1051204 Kosaka, T., et al. (2017) Response Heterogeneity of EGFR and HER2 Exon 20 Insertions to 1052 Covalent EGFR and HER2 Inhibitors. Cancer research 77, 2712-2721

1053205 Heist, R.S., et al. (2016) Acquired Resistance to Crizotinib in NSCLC with MET Exon 14 Skipping. 1054 Journal of thoracic oncology : official publication of the International Association for the Study of Lung 1055 Cancer 11, 1242-1245

1056206 Ou, S.I., et al. (2017) Emergence of Preexisting MET Y1230C Mutation as a Resistance Mechanism 1057 to Crizotinib in NSCLC with MET Exon 14 Skipping. Journal of thoracic oncology : official publication of 1058 the International Association for the Study of Lung Cancer 12, 137-140

1059207 Schrock, A.B., et al. (2017) Mutation of MET Y1230 as an Acquired Mechanism of Crizotinib 1060 Resistance in NSCLC with MET Exon 14 Skipping. Journal of thoracic oncology : official publication of 1061 the International Association for the Study of Lung Cancer 12, e89-e90 

and BRAF-altered lung cancers.

\begin{tabular}{|c|c|c|c|c|c|c|c|c|}
\hline Driver & Drug & $\begin{array}{c}\text { Clinical trial } \\
\text { identifier }^{\mathrm{a}} / \text { name (phase) }^{2}\end{array}$ & NSCLC, n & ORR, \% & mPFS, months & $\begin{array}{l}\text { Intracranial } \\
\text { disease } \\
\text { control, } \mathbf{n}(\%)\end{array}$ & $\begin{array}{c}\text { FDA } \\
\text { approval }\end{array}$ & Refs \\
\hline \multirow{8}{*}{ ROS1 } & \multirow{5}{*}{ Crizotinib } & EUROS1 (retrospective) & 32 & 80 & 9.1 & & \multirow{5}{*}{2016} & {$[24]$} \\
\hline & & $\begin{array}{c}\text { NCT00585195/PROFILE } \\
1001 \text { (I) }\end{array}$ & 50 & 72 & 19.2 & & & {$[22]$} \\
\hline & & NCT01945021 (II) & 127 & 71.7 & 15.9 & & & {$[25]$} \\
\hline & & NCT02183870/EUCROSS (II) & 34 & 70 & 20 & & & [26] \\
\hline & & NCT02034981/AcSé (II) & 78 & 47.2 & & & & [23] \\
\hline & Ceritinib & NCT01964157 (II) & $\begin{array}{c}32(30 \\
\text { crizotinib } \\
\text { naïve) }\end{array}$ & $\begin{array}{c}62 \text { (overall) and } 67 \\
\text { (naïve) }\end{array}$ & $\begin{array}{l}9.3 \text { (overall) and } \\
19.3 \text { (naïve) }\end{array}$ & $5 / 8(63 \%)$ & & {$[28]$} \\
\hline & Lorlatinib & NCT01970865 (I/II) & $\begin{array}{c}40 \\
\text { (previously } \\
\text { treated) and } \\
21 \text { (TKI } \\
\text { naïve) } \\
\end{array}$ & $\begin{array}{c}35 \text { (previously } \\
\text { treated) and } 62 \\
\text { (naïve) }\end{array}$ & $\begin{array}{c}8.5 \text { (previously } \\
\text { treated) and } 21 \\
\text { (naïve) }\end{array}$ & $\begin{array}{c}\text { Previously } \\
\text { treated: } \\
12 / 24(50 \%) \\
\text { Naïve: } 7 / 11 \\
(64 \%) \\
\end{array}$ & & {$[29]$} \\
\hline & Entrectinib & $\begin{array}{c}\text { NCT02097810/STARTRK-1 } \\
\text { (I), } \\
\text { NCT02568267/STARTRK-2 } \\
\text { (II) and EudraCT 2012- } \\
\text { 000148-88/ALKA-372-001 } \\
\text { (I) } \\
\end{array}$ & 53 & 77 & 19 & $11 / 20(55 \%)$ & 2019 & $\begin{array}{l}{[8,} \\
27]\end{array}$ \\
\hline \multirow[b]{3}{*}{ MET } & Crizotinib & $\begin{array}{c}\text { NCT00585195/PROFILE } \\
1001 \text { (I) }\end{array}$ & 65 & 32 & 7.3 & & & {$[73]$} \\
\hline & Tepotinib & NCT02864992/VISION (II) & 99 & 46 & 8.5 & $6 / 11(55 \%)$ & & [74] \\
\hline & Capmatinib & $\begin{array}{l}\text { NCT02414139/GEOMETRY } \\
\text { mono-1 study (II) }\end{array}$ & $\begin{array}{c}69 \\
\text { (previously } \\
\text { treated) and } \\
28 \text { (naïve) } \\
\end{array}$ & $\begin{array}{c}\text { 41(previously } \\
\text { treated) and } 64 \\
\text { (naïve) }\end{array}$ & $\begin{array}{c}5.4 \text { (previously } \\
\text { treated) and } 12.4 \\
\text { (naïve) }\end{array}$ & $12 / 13(92 \%)$ & 2020 & [9] \\
\hline \multirow{11}{*}{ RET } & \multirow{2}{*}{ Vandetanib } & UMIN000010095/LURET (II) & 19 & 47 & 4.7 & & & [185] \\
\hline & & NCT01823068 (II) & 17 & 18 & 4.5 & & & [186] \\
\hline & Cabozantinib & NCT01639508 (II) & 25 & 28 & 5.5 & & & [187] \\
\hline & Lenvatinib & NCT01877083 (II) & 25 & 16 & 7.3 & & & [188] \\
\hline & $\begin{array}{l}\text { Cabozantinib, } \\
\text { vandetanib, } \\
\text { sunitinib, } \\
\text { sorafenib, } \\
\text { alectinib, } \\
\text { lenvatinib, } \\
\text { nintedanib, } \\
\text { ponatinib or } \\
\text { regorafenib }\end{array}$ & GLORY (retrospective) & 53 & 26 & 2.3 & & & {$[54]$} \\
\hline & RXDX-105 & NCT01877811 (I/lb) & $\begin{array}{c}31 \text { (RET } \\
\text { inhibitor } \\
\text { naïve) } \\
\end{array}$ & $\begin{array}{l}19 \text { (0\% with KIF5B- } \\
\text { RET and } 67 \% \text { with } \\
\text { non-KIF5B partners) }\end{array}$ & & & & [189] \\
\hline & Alectinib & $\begin{array}{l}\text { UMIN000020628 (II) and } \\
\text { NCT03131206 (II) }\end{array}$ & ongoing & & & & & \\
\hline & \multirow{2}{*}{ Pralsetinib } & NCT03037385/ARROW (I/II) & $\begin{array}{c}116(26 \\
\text { naïve) }\end{array}$ & $\begin{array}{c}65 \text { (overall) and } 73 \\
\text { (naïve) }\end{array}$ & & $5 / 9(56 \%)$ & \multirow{2}{*}{2020} & {$[5]$} \\
\hline & & $\begin{array}{c}\text { NCT04222972/AcceleRET } \\
\text { (III) }\end{array}$ & ongoing & & & & & \\
\hline & \multirow[t]{2}{*}{ Selpercatinib } & $\begin{array}{c}\text { NCT03157128/LIBRETTO- } \\
001 \text { (I/II) }\end{array}$ & $\begin{array}{c}105 \\
\text { (previously } \\
\text { treated) and } \\
39 \text { (naïve) } \\
\end{array}$ & $\begin{array}{c}64 \text { (previously } \\
\text { treated) and } 85 \\
\text { (naïve) }\end{array}$ & $\begin{array}{c}16.5 \text { (previously } \\
\text { treated) }\end{array}$ & 10/11 (91\%) & \multirow[t]{2}{*}{2020} & {$[4]$} \\
\hline & & $\begin{array}{c}\text { NCT04194944/LIBRETTO- } \\
431 \text { (III) }\end{array}$ & ongoing & & & & & \\
\hline \multirow[b]{3}{*}{ NTRK } & \multirow{2}{*}{ Larotrectinib } & NCT02122913 (I) & 12 & 88 (pan cancer) & & & \multirow{2}{*}{2018} & {$[6]$} \\
\hline & & NCT02576431 (II) & ongoing & & & & & \\
\hline & Entrectinib & $\begin{array}{c}\text { NCT02097810/STARTRK-1 } \\
\text { (I), } \\
\text { NCT02568267/STARTRK-2 } \\
\text { (II) and EudraCT 2012- }\end{array}$ & 10 & 57 (pan cancer) & 11.2 (pan cancer) & & 2019 & [7] \\
\hline
\end{tabular}




\begin{tabular}{|c|c|c|c|c|c|c|c|c|}
\hline & & $\begin{array}{l}000148-88 / \text { ALKA-372-001 } \\
\text { (I) }\end{array}$ & & & & & & \\
\hline \multirow{10}{*}{ HER2 } & \multirow{3}{*}{ Afatinib } & Retrospective & 10 & 33 & & & & [190] \\
\hline & & Retrospective & 23 & 13 & & & & [191] \\
\hline & & NCT02369484/NICHE (II) & 13 & 53.8 & 15.9 & & & [192] \\
\hline & Dacomitinib & NCT00818441 (II) & 26 & 12 & 3 & & & [193] \\
\hline & Neratinib & NCT01953926/SUMMIT (II) & 26 & 4 & 5.5 & & & [194] \\
\hline & \multirow{2}{*}{ Pyrotinib } & NCT02535507 (II) & 15 & 53.3 & 6.4 & & & [195] \\
\hline & & NCT02834936 (II) & ongoing & & & & & \\
\hline & $\begin{array}{l}\text { Moborcetinib } \\
\text { (TAK-788) }\end{array}$ & NCT02716116 (I/II) & 21 & & & & & [95] \\
\hline & Poziotinib & NCT03066206 (II) & 12 & 42 & 5.6 & & & $\begin{array}{l}93, \\
196]\end{array}$ \\
\hline & $\begin{array}{l}\text { Trastuzumab- } \\
\text { deruxtecan }\end{array}$ & $\begin{array}{l}\text { NCT03505710/DESTINY- } \\
\text { Lung 01 (II) }\end{array}$ & 42 & 61.9 & 14 & & & [96] \\
\hline \multirow{8}{*}{ BRAF } & $\begin{array}{l}\text { Vemurafenib, } \\
\text { dabrafenib or } \\
\text { sorafenib }\end{array}$ & $\begin{array}{l}\text { European EURAF } \\
\text { (retrospective) }\end{array}$ & 35 & 53 & 5 & & & [105] \\
\hline & \multirow[t]{2}{*}{ Vemurafenib } & $\begin{array}{c}\text { NCT01524978/VE-BASKET } \\
\text { (II) }\end{array}$ & 62 (8 naïve) & $\begin{array}{c}37.1 \text { (overall), } \\
37 \text { (previously } \\
\text { treated) and } 37.5 \\
\text { (naïve) }\end{array}$ & $\begin{array}{c}6.5 \text { (overall), } \\
6.1 \text { (previously } \\
\text { treated) and } 12.9 \\
\text { (naïve) }\end{array}$ & & & [107] \\
\hline & & NCT02304809/AcSé (II) & 101 & 44.8 & 5.2 & & & [106] \\
\hline & Dabrafenib & NCT01336634 (II) & $\begin{array}{c}78 \\
\text { (previously } \\
\text { treated) and } \\
6 \text { (naïve) }\end{array}$ & $\begin{array}{l}33 \text { (previously } \\
\text { treated) } \\
\text { and } 67 \text { (naïve) }\end{array}$ & $\begin{array}{l}5.5 \text { (previously } \\
\text { treated) }\end{array}$ & & & [108] \\
\hline & $\begin{array}{l}\text { Dabrafenib } \\
\quad \text { and } \\
\text { trametinib }\end{array}$ & NCT01336634 (II) & $\begin{array}{c}57 \\
\text { (previously } \\
\text { treated) and } \\
36 \text { (naïve) } \\
\end{array}$ & $\begin{array}{l}63.2 \text { (previously } \\
\text { treated) and } 64 \\
\text { (naïve) }\end{array}$ & $\begin{array}{c}10.2 \text { (previously } \\
\text { treated) and } 10.9 \\
\text { (naïve) }\end{array}$ & & 2017 & $\begin{array}{l}{[3,} \\
109]\end{array}$ \\
\hline & $\begin{array}{c}\text { Encorafenib } \\
\text { and } \\
\text { binimetinib }\end{array}$ & NCT03915951/PHAROS (II) & ongoing & & & & & \\
\hline & Ulixertinib & NCT01781429 (I) & $\begin{array}{c}12 \\
\text { (BRAFi/MEKi } \\
\text { naïve) }\end{array}$ & 25 & & $1 / 12(8 \%)$ & & [114] \\
\hline & $\begin{array}{l}\text { LXH254 and } \\
\text { LLT462 }\end{array}$ & NCT02974725 (I) & ongoing & & & & & \\
\hline
\end{tabular}

1065

$1066{ }^{a}$ www.clinicaltrials.gov or www.umin.ac.jp

1067 
Figure 1: Comparative clinical efficacy of targeted therapies in ROS1, MET, RET, HER2 and BRAF-altered lung cancers. Each circle on the plot represents the efficacy of the indicated inhibitor inpatients for each specific driver (indicated with the different colors). Inspired by Figure 5 in Drilon A. and colleagues [57]. $X$ and $Y$ axis represent the objective response rate and the median progression-free survival duration, respectively, as reported from phase I and II clinical trials (see main text and Table 1 for details and references).

Figure 2: Schematic representation of the on-target resistance mutations and activity profile of kinase inhibitors targeting these specific resistance mutations among the different oncogenic drivers in NSCLC. A. The different types of mutations affecting the solvent-front, the gatekeeper residue, the activation loop or the DFG motifs are represented. Most resistance mutations seen in uncommon driver oncogenes have analogous resistance mutations identified in EGFR and ALK. B. Blue boxes indicate kinase inhibitor for which antitumoral activity against the indicated mutants has been reported in preclinical models (preclinical validation). Orange boxes designate kinase inhibitor that failed to show any inhibitory activity in vitro and/or in vivo (preclinical invalidation). Green boxes highlight reports of clinical activity (tumor shrinkage) while red dots indicate agents that failed to achieve an objective response in patients. Asterisks $\left({ }^{*}\right)$ indicate FDA approved drugs. Abbreviations: GK, gatekeeper; SF, solvent-front; AL, activation loop. References [36, 60, 75,

Figure 3: Signaling pathways driving resistance to targeted therapies in ROS1 (A), RET (B) and NTRK (C) fusions-positive NSCLC and MET (D), HER2 (E) and BRAF (F)-mutated NSCLC. Oncogenic drivers and their downstream signaling pathways are represented in blue and green, respectively. On-target resistance mutations as well as histological transformation are indicated (boxes). Protein alterations that have been implicated in the resistance to targeted agents are shown in orange. Potential therapeutic strategies are also highlighted in red. 


\section{Outstanding questions}

- Is it ethical to have an approved targeted treatment against an uncommon driver and not implement the diagnostic tests as routine to identify the patients?

- Are large randomized clinical trials comparing targeted agents with platinum-based chemotherapy needed in patients with rare oncogenic drivers?

- How could we design and validate combination treatments in the clinic that would outperform single agent therapies? Could we develop in parallel predictive biomarkers for stratifying patients?

- How can we improve the early identification of emergent on-target mutations? Could multiple samplings along the treatment through liquid biopsies and circulating DNA represent an alternative option to monitor resistance onset?

- Could concomitant low dosing therapies targeting different effectors within the RTKRAS-MAPK pathway be implemented in the clinic? 


\section{Highlights}

- Lung cancer is responsible of around 1.8 million deaths per year worldwide and is widely the leading cause of cancer-related mortality.

- The development of specific inhibitors is currently extending to less common oncogenic drivers (i.e. ROS1, MET, RET, NTRK, HER2 and BRAF) with an exponential growth of dedicated clinical trials.

- While, individually, each of these drivers appears with low prevalence, altogether, they account for $15 \%$ of all lung cancer cases, thereby affecting a large population of patients worldwide.

- Similar to what is observed with most targeted therapies directed against an oncogenic driver, the initial clinical response to targeted kinase inhibitors is almost always temporary and acquired resistance to these drugs invariably emerges, restricting their clinical utility.

- The characterization of intrinsic and acquired resistance relies on tissue or liquid biopsy upon disease progression. However genomic testing is not always capturingthe underlying mechanism of resistance.

- Both on-target and off-target resistance mechanisms to targeted therapies could be tackled in the clinic but the design of the most effective treatment still requires further evaluation. 
Figure 1

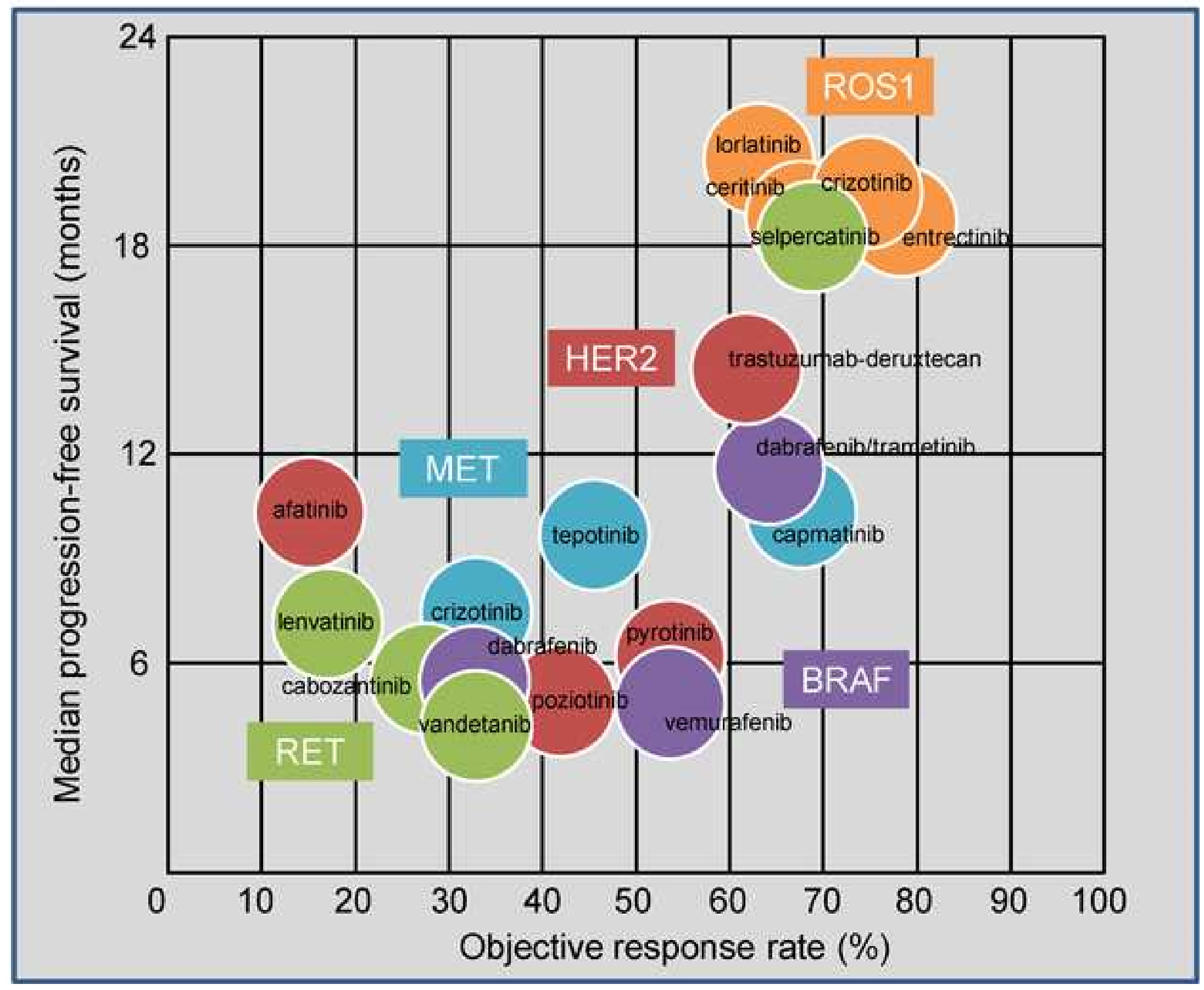


Figure 2

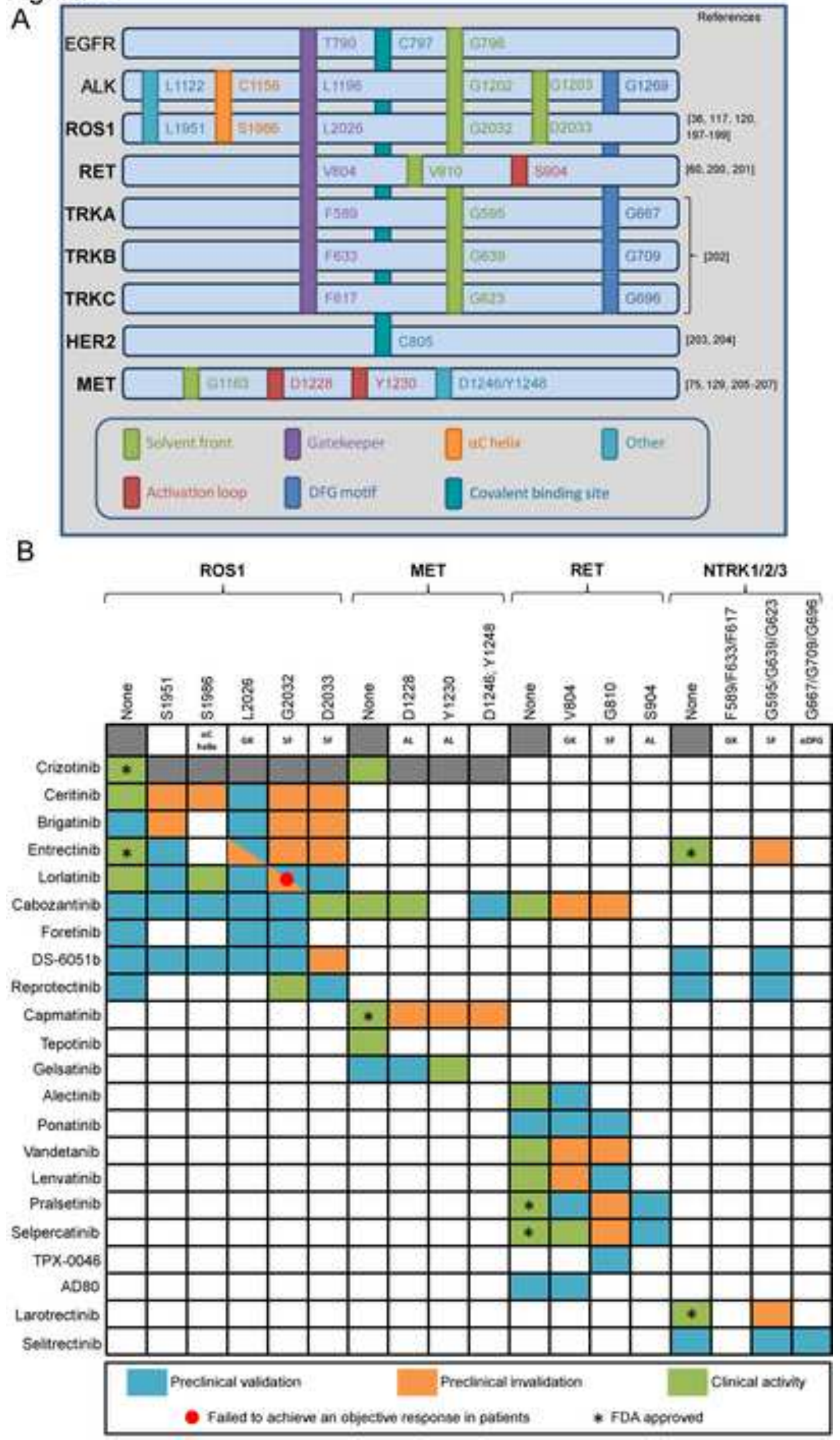




\section{Figure 3}
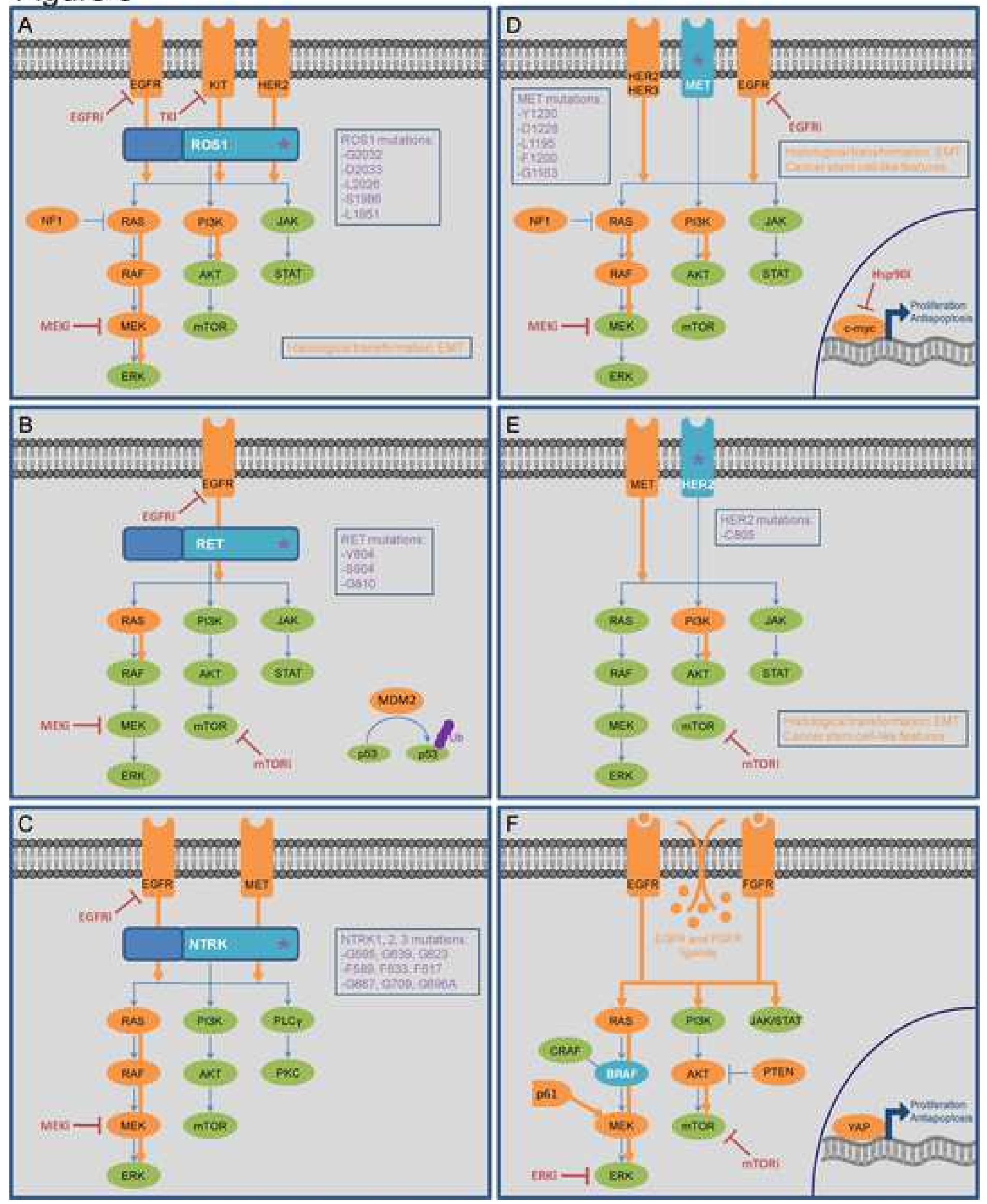